\title{
A Comparison of Different Shipment Policies in an Integrated Inventory System for Imperfect Quality Items with Inspection Errors
}

\author{
Yongwu Zhou, Xiong Zhang, and Zhaozhan Lin \\ School of Business Administration, South China University of Technology, Guangzhou 510641, China \\ Correspondence should be addressed to Zhaozhan Lin; zzlin-scut@hotmail.com
}

Received 16 May 2017; Accepted 4 July 2017; Published 24 September 2017

Academic Editor: Josefa Mula

Copyright (C) 2017 Yongwu Zhou et al. This is an open access article distributed under the Creative Commons Attribution License, which permits unrestricted use, distribution, and reproduction in any medium, provided the original work is properly cited.

Considering a production-ordering system where items are not perfect and quality screening is conducted with inspection errors, we develop integrated inventory models under different shipment policies and make a comprehensive comparison among them to select an optimal one, so as to improve the supply chain's performance. It is assumed that all items classified as defective during the screening process are sold as a single batch at a discounted price at the end of this screening process; items returned from the market are accumulating; and all of them are stored and sold as a single batch at a discounted price at the end of the next screening process. All the numerical results show that the proportional size shipment policy is always optimal, except for one situation where the difference between the vendor's and the buyer's unit inventory holding costs is considerably large. Therefore, we mainly recommend the proportional size shipment policy.

\section{Introduction}

The classical economic order or production quantity (EOQ/ $\mathrm{EPQ}$ ) model determines the optimal ordering or production quantity only from a buyer's or a vendor's perspective. In reality, the buyer and the vendor may make the productionordering decision together, so as to benefit their supply chain. Goyal [1-3] and Banerjee [4] extended the EOQ model to a two-staged integrated system and they quantitatively proved that the system could not obtain the minimal total cost when the vendor and the buyer made the inventory decision separately. Instead, only when both of them made the decision jointly could the optimal result be obtained.

For the integrated production-ordering supply chain system, during a production run, a vendor is requested to deliver consecutive batches of items to a buyer. The ordering quantities shipped to the buyer in the consecutive batches can be equal, unequal or conforming to a certain shipment policy. Such different shipment policies from the vendor to the buyer will account for different shipment costs and different inventory holding costs at the vendor's and buyer's ends, further affecting the total cost of their supply chain. As we know, transportation cost occupies quite a part of the total cost of a supply chain where the vendor ships items to the buyer and even a large part for some products in cold chain logistics and automobiles. Thus, it is important to select an optimal shipment policy so as to save cost for the integrated system and to improve the supply chain's performance.

The equal size shipment policy is easy to handle and manage but may not be cost-saving; the other unequal size shipment policies may be more cost-saving but are relatively hard to handle. $\mathrm{Lu}$ [5] considered the equal size shipment policy of the form $\{q, q, \ldots, q\}$ effective and cost-saving. Compared with the equal size shipment policy, Goyal [6] considered shipment policy of the form $\left\{q, \beta q, \beta^{2} q, \ldots, \beta^{n-1} q\right\}$ (the first shipment size is $q$, and the following shipment size is the previous shipment size multiplying a fixed factor $\beta$, where $\beta=P / D ; P$ is the production rate of the vendor and $D$ is the demand rate of the buyer; here we call it "the proportional size shipment policy") more cost-saving. Despite involving unequal size, this kind of shipment policy provides the buyer with smaller quantities to "be getting on with" during the early stage of a production cycle. Hill [7] recommended a more general shipment policy of the 
form $\left\{q, \lambda q, \lambda^{2} q, \ldots, \lambda^{n-1} q\right\}$ (the first shipment size is $q$, and the following shipment size is the previous shipment size multiplying a fixed factor $\lambda$, where $\lambda$ in $[1, P / D]$ ), which generated a lower total cost, compared with the equal size and proportional size shipment policy. What we should point out, however, is that the generality of this kind of shipment policy comes at the expense of its practicality. In order to get the optimal total cost, one needs to firstly get the optimal order number $n_{1}$ under the equal size shipment policy and $n_{2}$ under the proportional size shipment policy, respectively, and then do a full research over $\lambda$ in $[1, P / D]$ for each $n$ from $n_{1}$ to $n_{2}$. This approach is based on the assumption that the optimal $n$ for general $\lambda$ lies in $\left[n_{1}, n_{2}\right]$. Of course, this is only a conjecture. The complexity and difficulty to determine the optimal $\lambda$ and $n$ reduces the practicality of this shipment policy. Goyal and Nebebe [8] proposed another shipment policy of the form $\{q, \beta q, \ldots, \beta q\}$ (the first shipment size is $q$, and all the other successive shipment sizes are the same, with the first shipment size multiplying a factor $\beta$, where $\beta=P / D$; here we call it "the fixed-ratio size shipment policy"), which ensures a quick delivery of the first shipment size to the buyer and avoids excessive inventory level of higher order shipment at the buyer's end. Such a shipment policy is more cost-saving, compared with the equal size, proportional size, and Hill's [7] shipment policies under the same given circumstance. Hill [9] derived the globally optimal shipment policy producing a lowest total cost, which is very similar to the shipment policy of the form $\left\{q, \beta q, \beta^{2} q, \ldots, \beta^{m-1} q\right\}$ considered by Goyal and Szendrovits [10]. Their difference is that the size of the equal-sized shipments under Hill's [9] shipment policy in the end may not be the same as the last of the unequal-sized shipments. Other researchers also put insights into shipment policies for the integrated inventory system [11, 12]. Anyway, all these researches only consider the integrated system where all items are totally perfect. Also, their models for the integrated system include fixed transportation cost and vendor's fixed setup cost only and exclude variable transportation cost, vendor's variable production cost, and buyer's fixed ordering cost. These costs also need to be taken into consideration for the integrated system.

Actually, due to technology limitations and human or machine errors in the production process, it is impossible for all the items produced to be perfect [13-15]. Salameh and Jaber [16] (S-J model) extended the EOQ model to the situation where all items with a random fraction of defective items go through a $100 \%$ screening process, removing out defective items at the end of the screening process. Maddah and Jaber [17] (M-J model) corrected the S-J model with renewal-reward theory and extended the model by allowing several batches of imperfect quality items to be consolidated and shipped in one lot. From a unique perspective, Jaber et al. [18] extended the S-J model and the M-J model by applying the laws of thermodynamics where the demand rate is treated as a heat flow in a thermodynamic system, so as to capture the hidden costs of the inventory system. The S$\mathrm{J}$ model has received tremendous attention in dealing with imperfect quality items. With regard to the integrated system, Goyal et al. [19] incorporated the imperfect items into the single-vendor-single buyer integrated system; Ouyang et al. [20] used fuzzy method to describe the fraction of defective items; Rezaei and Davoodi [21] considered the scenario of a supply chain with multiple products and multiple suppliers. With regard to learning in screening or inspection, Jaber et al. [22] extended the S-J model by assuming that the fraction of defective items per lot reduces according to a learning curve; Khan et al. [23] further extended the S-J model to the case where there is learning in inspection, lost sales, and backorders; Konstantaras et al. [24] investigated an EOQ model with imperfect quality items and shortages, where the fraction of imperfect quality in each shipment reduces because of learning. With regard to quantity discount or trade credit, Lin [25] adopted a new inventory model for items with imperfect quality and quantity discounts where buyer has exerted power over its supplier; Zhou et al. [26] studied the EPQ models for items with imperfect quality and one-time-only discount; Chung [27] derived the EOQ model with defective items and partially permissible delay in payments linked to order quantity. With regard to treatment of nonconforming items, Jaber et al. [28] extended the SJ model with buy and repair option; Mondal et al. [29] incorporated marketing decisions with variable production cost for the inventory model with imperfect items; this model was rectified by Chang [30] and extended to the situation where lot-splitting shipments and different holding costs for good and defective items are considered. Other considerations and extensions related to imperfect quality items include deterioration $[31,32]$, shortages [33, 34], and multiechelon integrated inventory system [35]. A comprehensive and systematic review regarding EOQ model for imperfect quality items can be found in Khan et al. [36].

However, the quality inspection process is not absolutely error-free, because an inspector or a machine will make inspection errors unavoidable in this process. In practice, because of weak process control, deficient planned maintenance, inadequate work instructions, and/or damage in transit, the screening process is never perfect and likely to commit inspection errors. That is to say, a nondefective item may be classified as a defective one (this is called "Type One Error") and a defective item may be classified as a nondefective one (this is called "Type Two Error"). Based on the S-J model and renewal-reward theory, Khan et al. [37] took account of these two kinds of misclassifications in the inspection process and assumed that items returned from the market are stored with those classified as defective by an inspector. All of these nonconforming items are sold as a single batch at the end of each delivering cycle at a discounted price. J.-T. Hsu and L.-F. Hsu [38] further considered shortage backordering and sales returns. Nevertheless, the above models do not consider the integrated inventory system.

Recently, Khan et al. [39] considered two kinds of misclassifications mentioned above in the inspection process for the two-echelon integrated system where the equal size shipment policy is adopted. They assumed that a buyer starts screening at the start of a delivering cycle and discards or salvages the defective lot at the end of this screening process. However, the questions about how to develop the production-ordering models under the other shipment policies and how to make a 
valid comparison among these shipment policies and to select an optimal one remain unanswered. This paper develops the integrated production-ordering models under the equal size, fixed-ratio size, and proportional size shipment policy where items with imperfect quality go through quality inspection with inspection errors and makes a comprehensive comparison of different shipment policies. This paper undertakes a realistic assumption that all items classified as defective items during the screening process are sold as a single batch at a discounted price at the end of this screening process; items returned from the market are accumulating, and all of them are stored and sold as a single batch at a discounted price at the end of the next screening process. The contributions of this study are fourfold. First, it enriches the S-J model [16] to the integrated supply chain by considering inspection errors under different shipment policies. Second, it extends Khan et al's inspection models $[37,39]$ by dealing with the nonconforming items in a more realistic situation and adopting different shipment policies. Third, it improves the previous models dealing with shipment policies (Lu [5], Goyal and Nebebe [8], and Goyal [6]) to a more realistic situation where items are not perfect and quality inspection is conducted with inspection errors and makes a comprehensive comparison. Fourth, it offers practical evaluations to select an optimal shipment policy through numerical examples and sensitivity analyses efficiently and effectively. Such policies apply to manufacturing industries like automobile where imperfect items exist and quality inspection process reveals necessity and merit.

The rest of this paper is organized as follows. Section 2 presents the descriptions of the models.

Section 3 formulates mathematical models under different shipment policies. Section 4 provides numerical examples and sensitivity analyses. Section 5 comes to the conclusions. The proofs of the theorems are provided in Appendix.

\section{Model Description}

Consider an integrated system with a single vendor and a single buyer, where a vendor sells items through a buyer and ships items to the buyer by following the equal size, fixedratio size, and proportional size shipment policy, respectively. Items produced by the vendor have a random fraction of defective items. Items shipped from the vendor go through a $100 \%$ quality screening at the buyer's end with inspection errors including "Type One Error" and "Type Two Error" mentioned above. The problem is how to determine the optimal first shipment size and the number of shipments in a production cycle so as to minimize total cost of the integrated inventory system.

\section{Assumptions}

(1) Lead time is zero and time horizon is infinite. Since we consider infinite time horizon, there are infinite production cycles. One production cycle produces one batch of items, which are shipped consecutively by different shipments. This assumption is made to guarantee the seamless procession of the infinite production cycles over the infinite time horizon, so

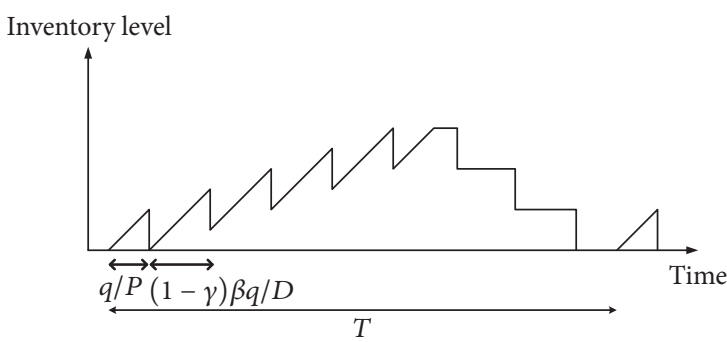

FIGURE 1: Inventory level of the vendor in a production cycle for the base model under the fixed-ratio size shipment policy.

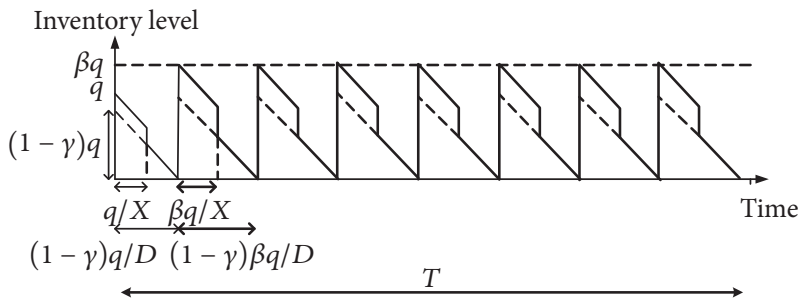

FIgURE 2: Inventory level of the buyer in a production cycle for the base model under the fixed-ratio size shipment policy.

that we can just take account of one production cycle to analyze the integrated inventory system.

(2) Single item with constant demand is considered, and shortages of items are not allowed. The assumption that shortages of items are not allowed in the inventory system implicitly requires that the time to consume the last shipment of one batch is not less than the time to produce the first shipment of the next batch, so that shortage will not occur during the last shipment in one production cycle.

\section{Mathematical Models}

3.1. The Base Models. In this subsection, we consider a situation where a $100 \%$ quality screening is conducted by the buyer and there is no inspection error. The defective items are discarded at the end of this screening process. The model under the equal size shipment policy has been developed by Khan et al. [39]. Here we develop the models under the fixedratio size and proportional size shipment policy, respectively.

3.1.1. Under the Fixed-Ratio Size Shipment Policy. Figures 1 and 2 describe inventory level of the vendor and the buyer, respectively. Because production rate of the vendor is higher than demand rate of the buyer, the vendor ships the first shipment size $q$ items to the buyer and accumulates inventory in the production time, reaching to a total batch size $W$ in a production run, which is supplied to the buyer by following the fixed-ratio size shipment policy. On the arrival of items, the buyer conducts a $100 \%$ screening and removes out the defective items at the end of this screening process.

In order to better calculate inventory level of the buyer and the vendor, we look at this problem from the perspective of inventory conservation of the integrated system. As 


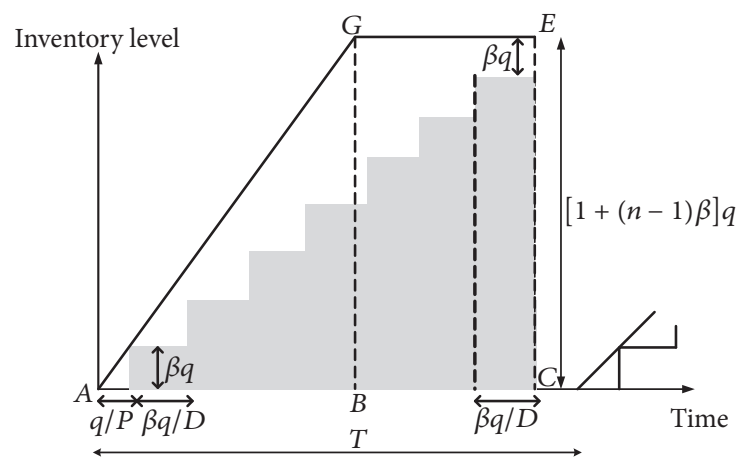

FIGURE 3: Inventory level of the integrated system in a production cycle for the base model under the fixed-ratio size shipment policy.

Figure 3 describes, the integrated system accumulates a total batch size $W$ produced by the vendor in a production run with the length $W / P$, and then its inventory keeps unchanged until the next production cycle, presented by area $A C E G$ in Figure 3. Items are shipped to the buyer following the shipment policy stepwise in this case, and the accumulated inventory level of this part is presented by the shadowed area in Figure 3. is

Total batch size shipped to the buyer in a production cycle

$$
W=q+(n-1) \beta q=[1+(n-1) \beta] q .
$$

Total inventory of the integrated system in a production cycle can be calculated by area $A C E G$ in Figure 3, and we can easily see that Area $_{A C G E}=$ Area $_{A B G}+$ Area $_{B C G E}$, the latter of which are given as

$$
\begin{aligned}
\text { Area }_{A B G} & =\frac{1}{2} \frac{[1+(n-1) \beta] q}{P} \cdot[1+(n-1) \beta] q \\
& =\frac{[1+(n-1) \beta]^{2} q^{2}}{2 P}, \\
\text { Area }_{B C G E} & =[1+(n-1) \beta] q \cdot\left[(n-1) \beta\left(\frac{q}{D}-\frac{q}{P}\right)\right] \\
& =\frac{(n-1) \beta[1+(n-1) \beta] q^{2}(P-D)}{P D} .
\end{aligned}
$$

Total inventory shipped to the buyer in a production cycle by the vendor can be calculated by the shadowed area in Figure 3, which is given as

$$
\begin{aligned}
(\beta q) & \frac{\beta q}{D}+(2 \beta q) \frac{\beta q}{D}+\cdots+[(n-1) \beta q] \frac{\beta q}{D} \\
= & \frac{n(n-1) \beta^{2} q^{2}}{2 D} .
\end{aligned}
$$

According to inventory conservation of the integrated system, total inventory of the vendor in a production cycle is the difference between total inventory of the integrated system and the buyer, which is given as

$$
\begin{aligned}
I_{v} & \\
= & \frac{[1+(n-1) \beta]^{2} q^{2}}{2 P} \\
& +\frac{(n-1) \beta[1+(n-1) \beta] q^{2}(P-D)}{P D} \\
& -\frac{n(n-1) \beta^{2} q^{2}}{2 D} \\
= & \frac{q^{2}}{2 D}\left\{\beta(n-1)[2+(n-2) \beta]-\frac{[(n-1) \beta]^{2}-1}{\beta}\right\} .
\end{aligned}
$$

Going through quality inspection process and removing out imperfect items, total inventory of the buyer now is given as

$$
\begin{aligned}
I_{b} & =\left[(\gamma q) \frac{q}{X}+(n-1)(\gamma \beta q) \frac{\beta q}{X}\right] \\
& +\left[\frac{(1-\gamma) q}{2} \frac{(1-\gamma) q}{D}\right. \\
& \left.+(n-1) \frac{(1-\gamma) \beta q}{2} \frac{(1-\gamma) \beta q}{D}\right]=q^{2}[1 \\
& \left.+(n-1) \beta^{2}\right]\left[\frac{\gamma}{X}+\frac{(1-\gamma)^{2}}{2 D}\right] .
\end{aligned}
$$

Total cost of the vendor in a production cycle includes fixed setup cost, variable production cost, and inventory holding cost, the sum of which is given as

$$
\begin{aligned}
C_{v} & =A_{v}+\frac{p[1+(n-1) \beta] q}{P} \\
& +\frac{h_{v} q^{2}}{2 D}\{\beta(n-1)[2+(n-2) \beta] \\
& \left.-\frac{[(n-1) \beta]^{2}-1}{\beta}\right\} .
\end{aligned}
$$

Total cost of the buyer in a production cycle includes fixed ordering cost, fixed and variable shipment cost, quality screening cost, and inventory holding cost, the sum of which is given as

$$
\begin{aligned}
C_{b}= & A_{b}+\{v[1+(n-1) \beta] q+n F\} \\
& +s[1+(n-1) \beta] q \\
& +h_{b} q^{2}\left[1+(n-1) \beta^{2}\right]\left[\frac{\gamma}{X}+\frac{(1-\gamma)^{2}}{2 D}\right] .
\end{aligned}
$$

Therefore, total cost of the integrated system in a production cycle is given as

$$
\mathrm{TC}=C_{v}+C_{b}
$$


Because fraction of defective items $\gamma$ is a random variable with probability density function $f(\gamma)$, we use its expected value $y$ and then we can obtain the expected total cost of the integrated system, which can be given as follows by combining (6), (7), and (8):

$$
\begin{aligned}
& E[\mathrm{TC}]=A_{v}+A_{b}+n F+\left(s+v+\frac{p}{P}\right)[1+(n-1) \beta] \\
& \cdot q+h_{v} \frac{q^{2}}{2 D}\{\beta(n-1)[2+(n-2) \beta] \\
& \left.-\frac{[(n-1) \beta]^{2}-1}{\beta}\right\}+h_{b} q^{2}\left[1+(n-1) \beta^{2}\right]\left(\frac{E[\gamma]}{X}\right. \\
& \left.+\frac{E\left[(1-\gamma)^{2}\right]}{2 D}\right) .
\end{aligned}
$$

The length of a production cycle is given as

$$
T=\frac{(1-\gamma)[1+(n-1) \beta] q}{D},
$$

and its expected value is given as

$$
E[T]=\frac{(1-E[\gamma])[1+(n-1) \beta] q}{D} .
$$

With renewal-reward theory, the average expected total cost of the integrated system is given as

$$
\begin{aligned}
& E[\text { ATC }]=\frac{E[\mathrm{TC}]}{E[T]}=\frac{\left(A_{v}+A_{b}+n F\right) D}{(1-E[r])[1+(n-1) \beta] q} \\
& +\frac{(s+v+p / P) D}{1-E[\gamma]} \\
& +\frac{h_{\nu} q\left\{\beta(n-1)[2+(n-2) \beta]-\left([(n-1) \beta]^{2}-1\right) / \beta\right\}}{2[1+(n-1) \beta](1-E[\gamma])} \\
& +\frac{h_{b} q}{1-E[\gamma]} \frac{1+(n-1) \beta^{2}}{1+(n-1) \beta}\left(\frac{D E[\gamma]}{X}+\frac{E\left[(1-\gamma)^{2}\right]}{2}\right) .
\end{aligned}
$$

It can be easily deduced that, in this case for the given integer $n$,

$$
\frac{\partial^{2}}{\partial q^{2}} E[\mathrm{ATC}]=\frac{2\left(A_{v}+A_{b}+n F\right) D}{(1-E[r])[1+(n-1) \beta] q^{3}}>0,
$$

so $E[$ ATC $]$ is convex with regard to $q$. By letting ( $\partial /$ $\partial q) E[\mathrm{ATC}]=0$, for the given integer $n, q$ can be obtained, so does the average expected total cost. By virtue of the convexity of (12), the optimal $E[\mathrm{ATC}]$ and $q$ can be obtained.

3.1.2. Under the Proportional Size Shipment Policy. Figures 4 and 5 describe inventory level of the vendor and the buyer, respectively. Because production rate of the vendor is higher than demand rate of the buyer, the vendor ships the first shipment size $q$ items to the buyer and accumulates inventory

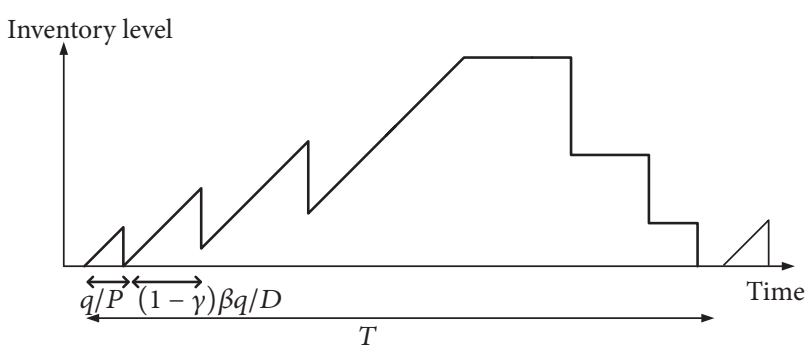

FIGURE 4: Inventory level of the vendor in a production cycle for the base model under the proportional size shipment policy.

in the production time, reaching to a total batch size $W$ in a production run, which is supplied to the buyer by following proportional size shipment policy. On the arrival of items, the buyer conducts a $100 \%$ screening and removes out the defective items at the end of this process.

Also, in terms of inventory conservation of the integrated system, as Figure 6 describes, we calculate total inventory of the vendor and the buyer as shown in Figures 4 and 5 .

Total batch size shipped to the buyer in a production cycle is

$$
W=q+\beta q+\beta^{2} q+\cdots+\beta^{n-1} q=\frac{\beta^{n}-1}{\beta-1} q .
$$

Total inventory of the integrated system in a production cycle can be calculated by area $A C E G$ in Figure 6 , and we can easily see that $A_{r e a} a_{A C G E}=A A_{A B G}+A_{A r e a} a_{B C G E}$, the latter of which are given as

$$
\begin{aligned}
\text { Area }_{A B G} & =\frac{1}{2} \frac{\left(\left(\beta^{n}-1\right) /(\beta-1)\right) q}{P} \cdot \frac{\beta^{n}-1}{\beta-1} q \\
& =\frac{\left(\left(\beta^{n}-1\right) /(\beta-1)\right)^{2} q^{2}}{2 P}, \\
\text { Area }_{B C G E} & =\frac{\beta^{n}-1}{\beta-1} q \cdot\left[\left(\beta+\cdots+\beta^{n-1}\right)\left(\frac{q}{D}-\frac{q}{P}\right)\right] \\
& =\frac{\left(\beta^{n}-1\right)\left(\beta^{n-1}-1\right) \beta q^{2}(P-D)}{(\beta-1)^{2} P D} .
\end{aligned}
$$

Total inventory shipped to the buyer in a production cycle by the vendor can be calculated by the shadowed area in Figure 6, which is given as

$$
\begin{gathered}
(\beta q) \frac{\beta q}{D}+\left(\beta q+\beta^{2} q\right) \frac{\beta^{2} q}{D}+\cdots \\
+\left(\beta q+\cdots+\beta^{n-1} q\right) \frac{\beta^{n-1} q}{D} \\
=\frac{\left(\beta^{n}-1\right)\left(\beta^{n-1}-1\right) \beta^{2} q^{2}}{\left(\beta^{2}-1\right)(\beta-1) D} .
\end{gathered}
$$

According to inventory conservation of the integrated system, total inventory of the vendor in a production cycle 


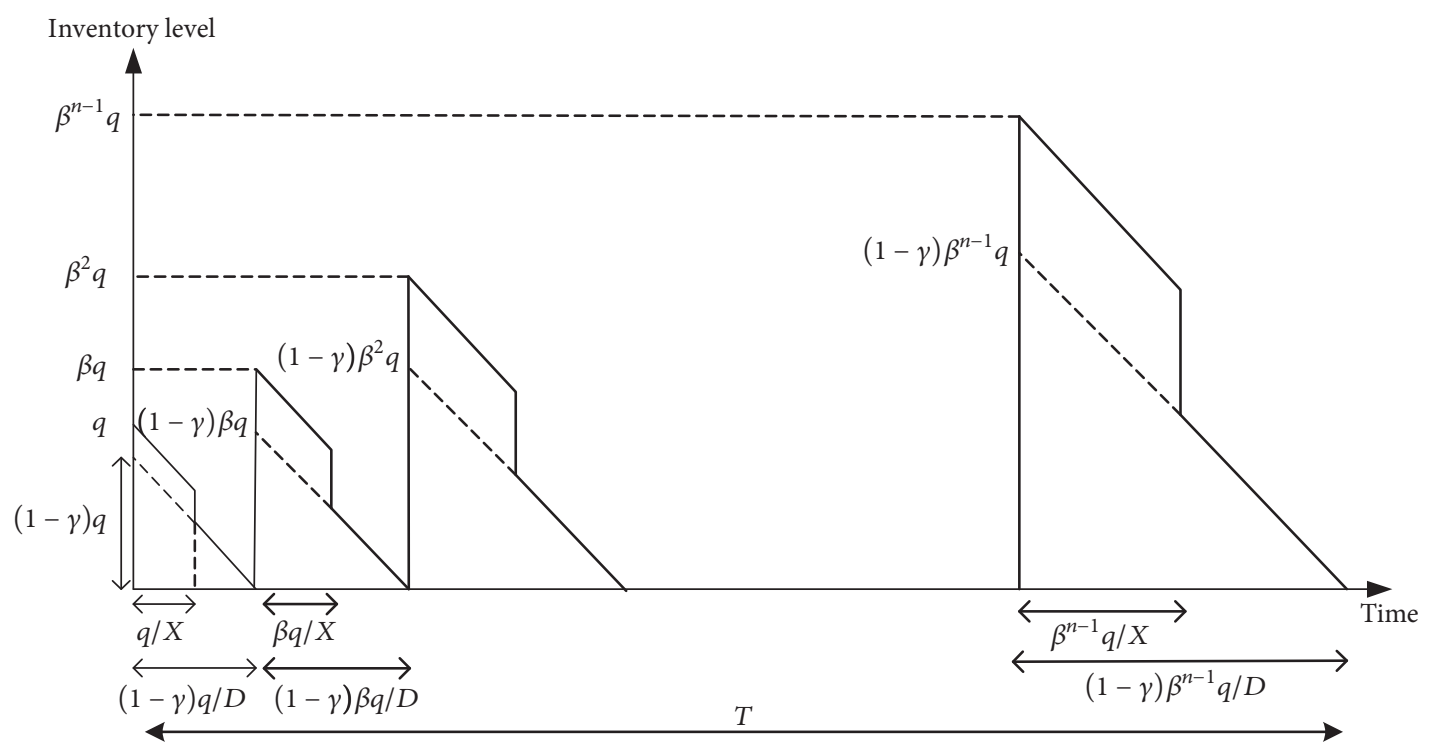

FIGURE 5: Inventory level of the buyer in a production cycle for the base model under the proportional size shipment policy.

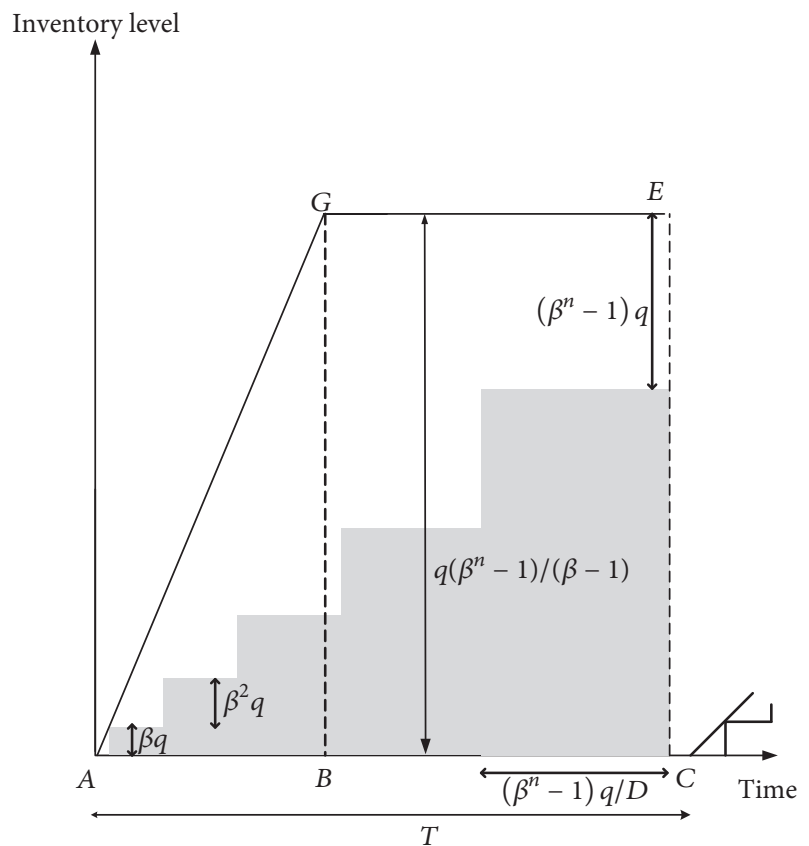

FIGURE 6: Inventory level of the integrated system in a production cycle for the base model under the proportional size shipment policy.

is the difference between total inventory of the integrated system and the buyer, which is given as

$$
\begin{aligned}
I_{v}= & \frac{\left(\left(\beta^{n}-1\right) /(\beta-1)\right)^{2} q^{2}}{2 P} \\
& +\frac{\left(\beta^{n}-1\right)\left(\beta^{n-1}-1\right) \beta q^{2}(P-D)}{(\beta-1)^{2} P D} \\
& -\frac{\left(\beta^{n}-1\right)\left(\beta^{n-1}-1\right) \beta^{2} q^{2}}{\left(\beta^{2}-1\right)(\beta-1) D}=\frac{q^{2}}{2 D} \frac{\left(\beta^{2 n}-1\right)}{\left(\beta^{2}-1\right) \beta} .
\end{aligned}
$$

Going through quality inspection process and removing out imperfect items, total inventory of the buyer now is given as

$$
\begin{aligned}
I_{v} & =\left[(\gamma q) \frac{q}{X}+(\gamma \beta q) \frac{\beta q}{X}+\left(\gamma \beta^{2} q\right) \frac{\beta^{2} q}{X}+\cdots\right. \\
& \left.+\left(\gamma \beta^{n-1} q\right) \frac{\beta^{n-1} q}{X}\right]+\left[\frac{(1-\gamma) q}{2} \frac{(1-\gamma) q}{D}\right. \\
& +\frac{(1-\gamma) \beta q}{2} \frac{(1-\gamma) \beta q}{D}+\frac{(1-\gamma) \beta^{2} q}{2} \frac{(1-\gamma) \beta^{2} q}{D} \\
& \left.+\cdots+\frac{(1-\gamma) \beta^{n-1} q}{2} \frac{(1-\gamma) \beta^{n-1} q}{D}\right]=q^{2} \\
& +\frac{\beta^{2 n}-1}{\beta^{2}-1}\left[\frac{\gamma}{X}+\frac{(1-\gamma)^{2}}{2 D}\right] .
\end{aligned}
$$

Total cost of the vendor in a production cycle includes fixed setup cost, variable production cost, and inventory holding cost, the sum of which is given as

$$
\begin{aligned}
C_{v}= & A_{v}+\frac{p\left(\left(\beta^{n}-1\right) /(\beta-1)\right) q}{P} \\
& +\frac{h_{v} q^{2}}{2 D} \frac{\left(\beta^{2 n}-1\right)}{\left(\beta^{2}-1\right) \beta} .
\end{aligned}
$$

Total cost of the buyer in a production cycle includes fixed ordering cost, fixed and variable shipment cost, quality screening cost, and inventory holding cost, the sum of which 


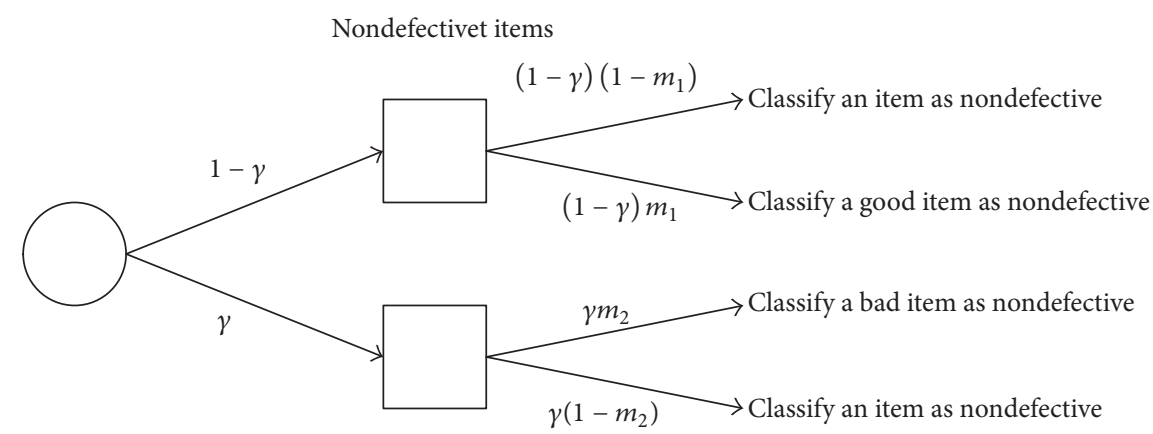

Defective items

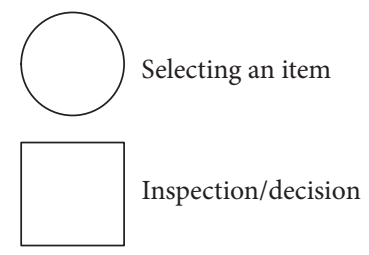

FIGURE 7: Four possibilities in the inspection process.

is given as

$$
\begin{aligned}
C_{b}= & A_{b}+\left(v \frac{\beta^{n}-1}{\beta-1} q+n F\right)+s \frac{\beta^{n}-1}{\beta-1} q \\
& +h_{b} q^{2} \frac{\beta^{2 n}-1}{\beta^{2}-1}\left[\frac{\gamma}{X}+\frac{(1-\gamma)^{2}}{2 D}\right] .
\end{aligned}
$$

Therefore, total cost of the integrated system in a production cycle is given as

$$
\mathrm{TC}=C_{v}+C_{b} .
$$

Because fraction of defective items $\gamma$ is a random variable with probability density function $f(\gamma)$, we use its expected value and then we can obtain the expected total cost of the integrated system, which can be given as follows by combining (19), (20), and (21):

$$
\begin{aligned}
E[\mathrm{TC}]= & A_{v}+A_{b}+n F+\left(s+v+\frac{p}{P}\right) \frac{\beta^{n}-1}{\beta-1} q \\
& +\frac{h_{v} q^{2}}{2 D} \frac{\left(\beta^{2 n}-1\right)}{\left(\beta^{2}-1\right) \beta} \\
& +h_{b} q^{2} \frac{\beta^{2 n}-1}{\beta^{2}-1}\left(\frac{E[\gamma]}{X}+\frac{E\left[(1-\gamma)^{2}\right]}{2 D}\right) .
\end{aligned}
$$

The length of a production cycle is given as

$$
T=\frac{(1-\gamma)\left(\left(\beta^{n}-1\right) /(\beta-1)\right) q}{D},
$$

and its expected value is given as

$$
E[T]=\frac{(1-E[\gamma])\left(\left(\beta^{n}-1\right) /(\beta-1)\right) q}{D} .
$$

With renewal-reward theory, the average expected total cost of the integrated system is given as

$$
\begin{aligned}
E[\mathrm{ATC}] & =\frac{E[\mathrm{TC}]}{E[T]} \\
= & \frac{\left(A_{v}+A_{b}+n F\right) D}{(1-E[r])\left(\left(\beta^{n}-1\right) /(\beta-1)\right) q} \\
& +\frac{(s+v+p / P) D}{1-E[r]}+\frac{h_{v} q}{2(1-E[r])} \frac{\beta^{n}+1}{(\beta+1) \beta} \\
& +\frac{h_{b} q}{1-E[r]} \frac{\beta^{n}+1}{\beta+1}\left(\frac{D E[\gamma]}{X}+\frac{E\left[(1-\gamma)^{2}\right]}{2}\right) .
\end{aligned}
$$

It can be easily deduced that in this case, for the given integer $n$,

$$
\begin{aligned}
\frac{\partial^{2}}{\partial q^{2}} E[\text { ATC }] & =\frac{2\left(A_{v}+A_{b}+n F\right) D}{(1-E[r])\left(\left(\beta^{n}-1\right) /(\beta-1)\right) q^{3}} \\
& >0,
\end{aligned}
$$

so $E[\mathrm{ATC}]$ is convex with regard to $q$. By letting $(\partial /$ $\partial q) E[\mathrm{ATC}]=0$, for the given integer $n, q$ can be obtained, so does the average expected total cost. By virtue of the convexity of (25), the optimal E[ATC] and $q$ can be obtained.

3.2. Models with Inspection Errors. In this subsection, we consider a situation where a $100 \%$ quality screening is conducted by the buyer with inspection errors. Committing inspection errors indicates that a nondefective item may be classified as a defective one, while a defective item may be classified as a nondefective one. There are four possibilities occurring in the inspection process, as Figure 7 depicts. The nonconforming items include those classified as defective 
during the screening process and those returned from the market. It is assumed that all the items classified as defective during the screening process are sold as a single batch at a discounted price at the end of this screening process. Items returned from the market are accumulating, and all of them are stored and sold as a single batch at a discounted price at the end of the next screening process. The models under three different shipment policies are updated with the above realistic considerations based on the base models developed in Section 3.1.

Fraction of defective items perceived by an inspector or a machine will be

$$
\gamma_{e}=(1-\gamma) m_{1}+\gamma\left(1-m_{2}\right)
$$

Because $\gamma, m_{1}$, and $m_{2}$ are random variables, and these random variables are independent, by using their expected values, (27) can be rewritten as

$$
E\left[\gamma_{e}\right]=(1-E[\gamma]) E\left[m_{1}\right]+E[\gamma]\left(1-E\left[m_{2}\right]\right)
$$

3.2.1. Under the Equal Size Shipment Policy. Under this shipment policy, the expected length of a production cycle is given as

$$
\begin{aligned}
& E[T]=\frac{\left(1-E\left[\gamma_{e}\right]\right) n q}{D} \\
& =\frac{\left\{1-(1-E[\gamma]) E\left[m_{1}\right]-E[\gamma]\left(1-E\left[m_{2}\right]\right)\right\} n q}{D} .
\end{aligned}
$$

The total number of items that are classified as defective is given as

$$
\begin{aligned}
B & =\sum_{i=1}^{n} B_{i}=\left[(1-\gamma) m_{1}+\gamma\left(1-m_{2}\right)\right] \sum_{i=1}^{n} q_{i} \\
& =\left[(1-\gamma) m_{1}+\gamma\left(1-m_{2}\right)\right] n q .
\end{aligned}
$$

The total number of items that are returned from the market is given as

$$
E=\sum_{i=1}^{n} E_{i}=\gamma m_{2} \sum_{i=1}^{n} q_{i}=\gamma m_{2} n q
$$

The revenue from selling these nonconforming items at a discounted price, which include those classified as defective and those returned from the market, is given as

$$
R_{1}=z(B+E)=\left[(1-\gamma) m_{1}+\gamma\right] n q z .
$$

The revenue from selling the good items is given as

$$
R_{2}=\left[(1-\gamma)\left(1-m_{1}\right)+\gamma m_{2}\right] n q y .
$$

Thus, total revenue of the integrated system will be

$$
\begin{aligned}
R= & R_{1}+R_{2} \\
= & {\left[(1-\gamma) m_{1}+\gamma\right] n q z } \\
& +\left[(1-\gamma)\left(1-m_{1}\right)+\gamma m_{2}\right] n q y .
\end{aligned}
$$
will be

The expected average total profit of the integrated system

$$
E[\mathrm{ATR}]=\frac{E[R]}{E[T]}=\frac{\left(\left\{(1-E[\gamma]) E\left[m_{1}\right]+E[\gamma]\right\} z+\left\{(1-E[\gamma])\left(1-E\left[m_{1}\right]\right)+\gamma E\left[m_{2}\right]\right\} y\right) D}{\left(1-E\left[\gamma_{e}\right]\right)}
$$

Equation (35) is independent of the decision variables, the first shipment size $q$, and ordering number $n$. Thus, we minimize the expected average total cost of the integrated system of all the models under different shipment policies as the objective.

In order to meet demand of the buyer, production rate of the vendor is required to satisfy: $P\left(1-E\left[\gamma_{e}\right]\right)>D$. Total inventory holding cost also includes the part of these items returned from the market in a production cycle, which is $(h E / 2)((1-\gamma) q / D)$, as we can see from Figure 8 .

The average expected total cost of the integrated system should be updated as

$$
\begin{aligned}
E[\operatorname{ATC}(n, q)]= & \frac{\left(A_{v}+A_{b}+n F\right) D}{\left(1-E\left[\gamma_{e}\right]\right) n q}+\frac{(s+v+p / P) D}{1-E\left[\gamma_{e}\right]}+\frac{c_{a} E[\gamma] E\left[m_{2}\right] D}{1-E\left[\gamma_{e}\right]}+\frac{c_{r}(1-E[\gamma]) E\left[m_{1}\right] D}{1-E\left[\gamma_{e}\right]} \\
& +\frac{q\left\{h_{v}[n-1-(n-2)(D / P)]+h_{b}\left[\left(1-E\left[\gamma_{e}\right]\right)^{2}+2 D E\left[\gamma_{e}\right] / X+E\left[m_{2}\right] E[\gamma](1-E[\gamma])\right]\right\}}{2\left(1-E\left[\gamma_{e}\right]\right)} .
\end{aligned}
$$


We have the following theorem.

Theorem 1. For given $n$, the average expected total cost of the integrated system is convex with regard to $q$. (The proof can be seen in Appendix.)

Based on Theorem 1, the solution procedure of the optimal average expected total cost of the integrated system in this case can be determined by the following algorithm.

\section{Algorithm 2.}

Step 1. Input the values of all the parameters, and set $n=1$ and $n=2$.

Step 2. Calculate $q$ from (A.3), and let $q(n)$ denote the result.

Step 3. Calculate $E[\mathrm{ATC}]$ from (36), and let $E[\operatorname{ATC}(n, q(n))]$ denote the result.

Step 4. If $E[\operatorname{ATC}(n-1, q(n-1))]>E[\operatorname{ATC}(n, q(n))]$, then set $n=n+1$ and go back to Step 2; otherwise, stop and set $n^{*}=n-1, q^{*}=q(n-1), E[\mathrm{ATC}]^{*}=E[\operatorname{ATC}(n-1, q(n-1))]$.
Thus, we get the optimal $n^{*}, q^{*}$, and $E[\text { ATC }]^{*}$ in this case.

3.2.2. Under the Fixed-Ratio Size Shipment Policy. Under this shipment policy, the expected length of a production cycle is given as

$$
\begin{aligned}
& E[T]=\frac{\left(1-E\left[\gamma_{e}\right]\right)[1+(n-1) \beta] q}{D} \\
& =\frac{\left\{1-(1-E[\gamma]) E\left[m_{1}\right]-E[\gamma]\left(1-E\left[m_{2}\right]\right)\right\}[1+(n-1) \beta] q}{D} .
\end{aligned}
$$

In order to meet demand of the buyer, production rate of the vendor is required to satisfy $P\left(1-E\left[\gamma_{e}\right]\right)>D$. Total inventory holding cost also includes the part of these items returned from the market in a production cycle, which is $(h / 2)\left[E_{1}(1-\gamma) q / D+\left(\sum_{i=2}^{n} E_{i}(1-\gamma) \beta q\right) / D\right]$, as we can see from Figure 9.

The average expected total cost of the integrated system should be updated as

$$
\begin{aligned}
& E[\operatorname{ATC}(n, q)]=\frac{\left(A_{v}+A_{b}+n F\right) D}{\left(1-E\left[\gamma_{e}\right]\right)[1+(n-1) \beta] q}+\frac{(s+v+p / P) D}{1-E\left[\gamma_{e}\right]}+\frac{c_{a} E[\gamma] E\left[m_{2}\right] D}{1-E\left[\gamma_{e}\right]}+\frac{c_{r}(1-E[\gamma]) E\left[m_{1}\right] D}{1-E\left[\gamma_{e}\right]} \\
& +\frac{q h_{v}\left\{\beta(n-1)[2+(n-2) \beta]-\left([(n-1) \beta]^{2}-1\right) / \beta\right\}+h_{b}\left[1+(n-1) \beta^{2}\right]\left(2 D E\left[\gamma_{e}\right] / X+E\left[\left(1-\gamma_{e}\right)^{2}\right]+E\left[m_{2}\right] E[\gamma](1-E[\gamma])\right)}{2[1+(n-1) \beta]\left(1-E\left[\gamma_{e}\right]\right)} .
\end{aligned}
$$

We have the following theorem.

Theorem 3. For the given $n$, the average expected total cost of the integrated system is convex with regard to $q$. (The proof can be seen in Appendix.)

Based on Theorem 3, the solution procedure of the optimal average expected total cost of the integrated system in this case can be determined by the following algorithm.

\section{Algorithm 4.}

Step 1. Input the values of all the parameters, and set $n=1$ and $n=2$.

$$
E[T]=\frac{\left(1-E\left[\gamma_{e}\right]\right)\left(\left(\beta^{n}-1\right) /(\beta-1)\right) q}{D}=\frac{\left\{1-(1-E[\gamma]) E\left[m_{1}\right]-E[\gamma]\left(1-E\left[m_{2}\right]\right)\right\}\left(\left(\beta^{n}-1\right) /(\beta-1)\right) q}{D}
$$

Step 2. Calculate $q$ from (A.6), and let $q(n)$ denote the result.

Step 3. Calculate $E[$ ATC] from (38), and let $E[\operatorname{ATC}(n, q(n))]$ denote the result.

Step 4. If $E[\operatorname{ATC}(n-1, q(n-1))]>E[\operatorname{ATC}(n, q(n))]$, then set $n=n+1$ and go back to Step 2; otherwise, stop and set $n^{*}=n-1, q^{*}=q(n-1), E[\mathrm{ATC}]^{*}=E[\operatorname{ATC}(n-1, q(n-1))]$.

Thus, we get the optimal $n^{*}, q^{*}$, and $E[\text { ATC }]^{*}$ in this case.

3.2.3. Under the Proportional Size Shipment Policy. Under this shipment policy, the expected length of a production cycle is given as
In order to meet demand of the buyer, production rate of the vendor is required to satisfy $P\left(1-E\left[\gamma_{e}\right]\right)>D$. Total inventory holding cost also includes the part of these items returned from the market in a production cycle, which is $(h / 2)\left[E_{1}(1-\gamma) q / D+\left(\sum_{i=2}^{n} E_{i}(1-\gamma) \beta^{i-1} q\right) / D\right]$, as we can see from Figure 10.

The average expected total cost of the integrated system should be updated as 


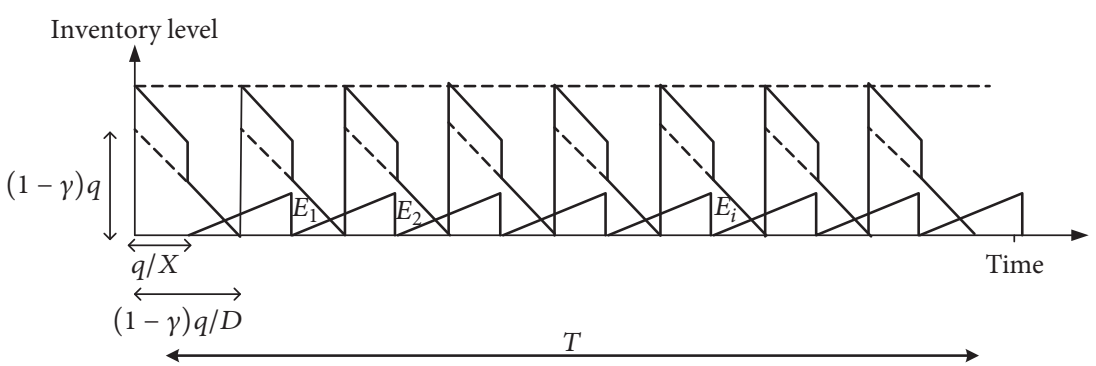

FIGURE 8: Inventory level of the buyer in a production cycle for the model with inspection errors under the equal size shipment policy.

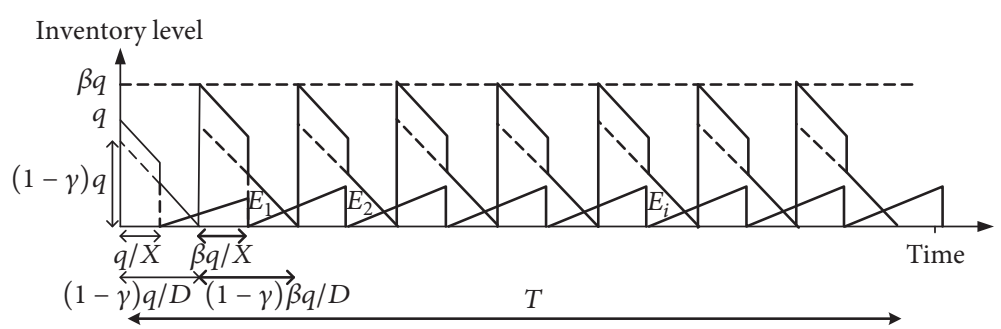

FIGURE 9: Inventory level of the buyer in a production cycle for the model with inspection errors under the fixed-ratio size shipment policy.

$$
\begin{aligned}
E[\operatorname{ATC}(n, q)]= & \frac{\left(A_{v}+A_{b}+n F\right) D}{\left(1-E\left[\gamma_{e}\right]\right)\left(\left(\beta^{n}-1\right) /(\beta-1)\right) q}+\frac{(s+v+p / P) D}{1-E\left[\gamma_{e}\right]}+\frac{c_{a} E[r] E\left[m_{2}\right] D}{1-E\left[\gamma_{e}\right]}+\frac{c_{r}(1-E[\gamma]) E\left[m_{1}\right] D}{1-E\left[\gamma_{e}\right]} \\
& +\frac{q\left(\left(\beta^{n}+1\right) /(\beta+1)\right)\left\{h_{v} / \beta+h_{b}\left[2 D E\left[\gamma_{e}\right] / X+E\left[\left(1-\gamma_{e}\right)^{2}\right]+E\left[m_{2}\right] E[\gamma](1-E[\gamma])\right]\right\}}{2\left(1-E\left[\gamma_{e}\right]\right)} .
\end{aligned}
$$

We have the following theorem.

Theorem 5. For the given $n$, the average expected total cost of the integrated system is convex with regard to $q$. (The proof can be seen in Appendix.)

Based on Theorem 5, the solution procedure of the optimal average expected total cost of the integrated system in this case can be determined by the following algorithm.

\section{Algorithm 6.}

Step 1. Input the values of all the parameters, and set $n=1$ and $n=2$.

Step 2. Calculate $q$ from (A.9), and let $q(n)$ denote the result.

Step 3. Calculate $E[\mathrm{ATC}]$ from (40), and let $E[\operatorname{ATC}(n, q(n))]$ denote the result.

Step 4. If $E[\operatorname{ATC}(n-1, q(n-1))]>E[\operatorname{ATC}(n, q(n))]$, then set $n=n+1$ and go back to Step 2; otherwise, stop and set $n^{*}=n-1, q^{*}=q(n-1), E[\mathrm{ATC}]^{*}=E[\operatorname{ATC}(n-1, q(n-1))]$.

Thus, we get the optimal $n^{*}, q^{*}$, and $E[\text { ATC }]^{*}$ in this case.

\section{Numerical Examples}

For brevity, let shipment policies 1,2, and 3 denote the equal size, fixed-ratio size, and proportional size shipment policy, respectively. For a better comparison, we use most of the following parameters from Hill [9], Goyal [40], Salameh and Jaber [16], and Khan et al. [39], as follows.

The fraction of defective items and probabilities of two kinds of misclassifications follow uniform distributions as follows:

$$
\begin{gathered}
f(\gamma)= \begin{cases}\frac{1}{0.2-0}, & 0 \leq x \leq 0.2 \\
0, & \text { otherwise, }\end{cases} \\
f\left(m_{1}\right)= \begin{cases}\frac{1}{0.1-0}, & 0 \leq x \leq 0.1 \\
0, & \text { otherwise, }\end{cases} \\
f\left(m_{2}\right)= \begin{cases}\frac{1}{0.1-0}, & 0 \leq x \leq 0.1 \\
0, & \text { otherwise. }\end{cases}
\end{gathered}
$$

It is clear that $E[\gamma]=0.1, E\left[m_{1}\right]=E\left[m_{2}\right]=0.05$. Other values of parameters are given as follows.

$D=1000$ (unit/year), $P=3200$ (unit/year), $p=$ 1000 (\$/year), $X=175200$ (unit/year), $A_{v}=400$ (\$/cycle), $A_{b}=25$ (\$/cycle), $h_{v}=4$ (\$/unit/year), $h_{b}=5$ (\$/unit/year), 


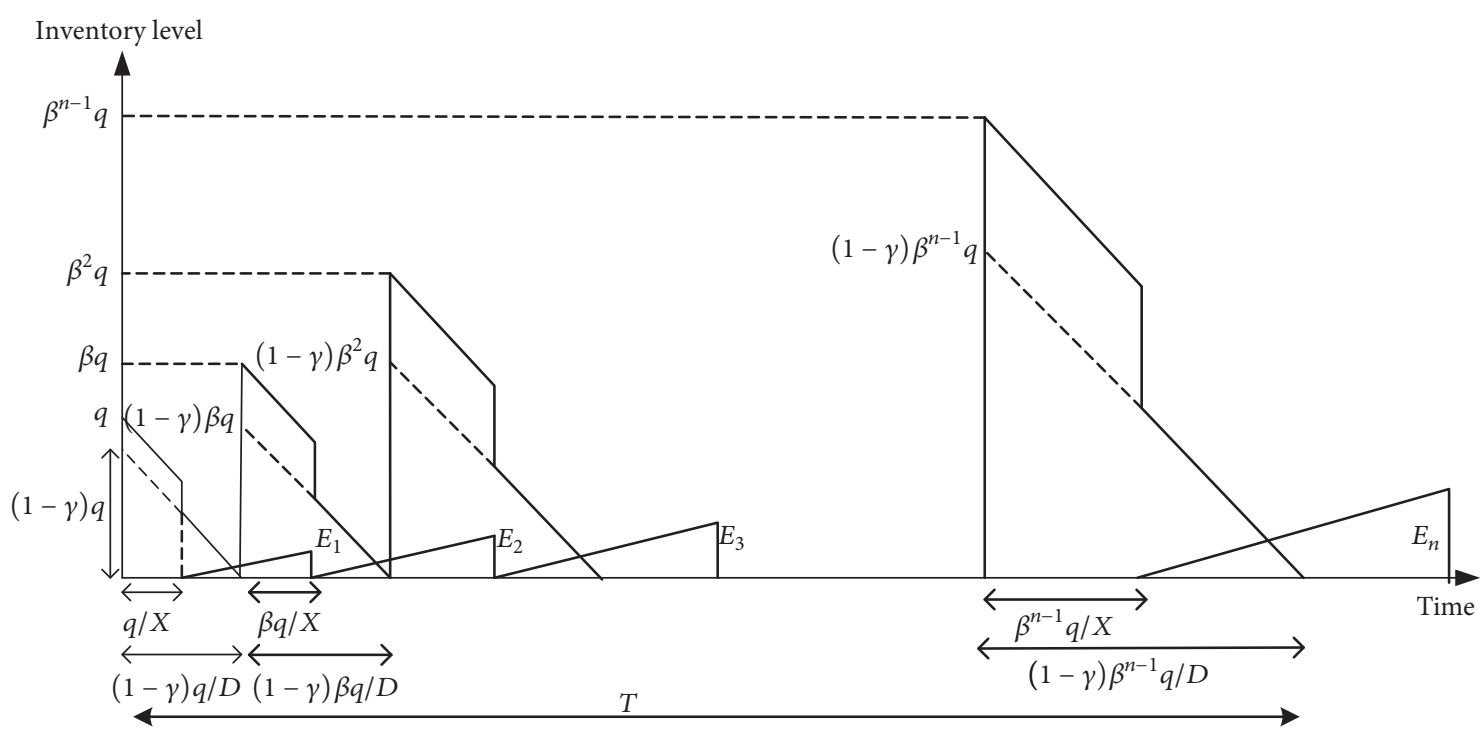

FIGURE 10: Inventory level of the buyer in a production cycle for the model with inspection errors under the proportional size shipment policy.

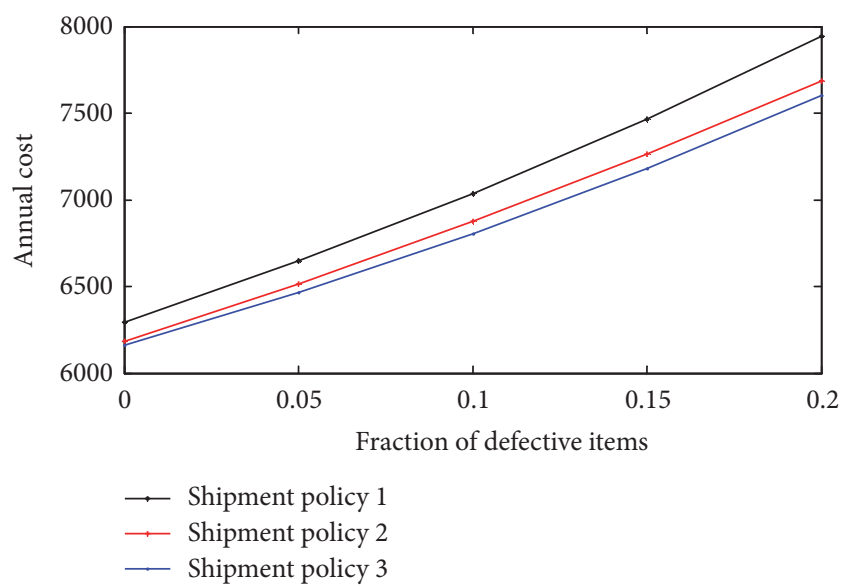

FIGURE 11: Impact of fraction of defective items.

$s=0.5$ (\$/unit), $v=2$ (\$/unit), $F=25$ (\$/shipment), $c_{r}=$ 25 (\$/unit), $c_{a}=50$ (\$/unit).

Before undertaking the numerical examples, here we need to point out that when there is quality inspection without committing inspection errors, which means that probabilities of two kinds of misclassifications reduce to zero $\left(m_{1}=0, m_{2}=0, c_{r}=0, c_{a}=0\right)$, the models with inspection errors will degenerate into the base models; further, when all the items are perfect and there is no quality inspection, which means that fraction of defective items declines to zero $(\gamma=0, s=0, X \rightarrow+\infty)$, and the integrated system considers fixed transportation cost and vendor's fixed setup cost only, which means that the variable transportation cost, the vendor's variable production cost, and the buyer's fixed ordering cost are neglected ( $\left.v=0, p=0, A_{b}=0\right)$, the base models will degenerate into the models with perfect items, which were developed by Lu [5], Goyal and Nebebe [8], and Goyal [6], respectively.

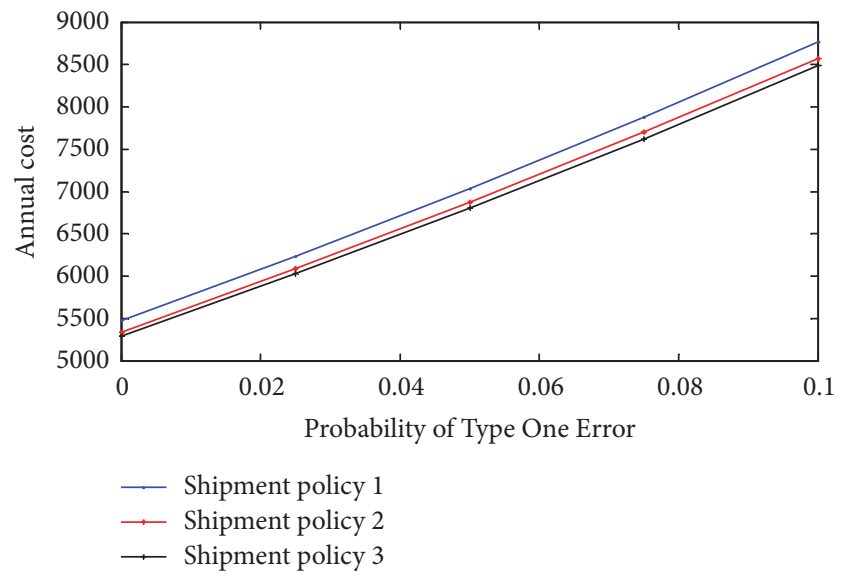

Figure 12: Impact of probability of Type One Error.

Let $\varepsilon$ denote the percentage differences of the other shipment policies with respect to the optimal one. Following the solution procedures provided in Section 3, we obtain the following optimal results of $n^{*}, q^{*}$, and $E[\text { ATC }]^{*}$ in Table 1 .

The results of the models with perfect items, which can be obtained by degenerating the base models by setting the corresponding values mentioned above, are consistent with those of Lu [5], Goyal and Nebebe [8], and Goyal [6], respectively. From Table 1, we can see that, for the models with perfect items, the fixed-ratio size shipment policy is optimal; for the base models and the models with inspection errors, the proportional size shipment policy is optimal.

To make a comprehensive comparison of the different shipment policies in the presence of imperfect quality items with inspection errors, we take the models with inspection errors to analyze how different parameters influence the optimal results.

Table 2, Figures 11, 12, and 13 demonstrate the impacts of fraction of defective items and probabilities of two kinds 
TABLE 1: Optimal results of different models under different shipment policies.

\begin{tabular}{|c|c|c|c|c|c|c|c|}
\hline Scenario & Policy & $n^{*}$ & $q^{*}$ & Structure & Total size & $E[\mathrm{ATC}]^{*}$ & $\varepsilon$ \\
\hline \multirow{3}{*}{ Models with perfect items } & 1 & 5 & 111 & $\{111,111,111,111,111\}$ & 555 & 1903 & $4.68 \%$ \\
\hline & 2 & 4 & 52 & $\{52,166,166,166,166\}$ & 550 & 1808 & Optimal \\
\hline & 3 & 3 & 36 & $\{36,115,369\}$ & 520 & 1818 & $4.95 \%$ \\
\hline \multirow{3}{*}{ Base models } & 1 & 4 & 139 & $\{139,139,139,139\}$ & 556 & 5221 & $3.7 \%$ \\
\hline & 2 & 3 & 77 & $\{77,246,246\}$ & 569 & 5084 & $1 \%$ \\
\hline & 3 & 3 & 40 & $\{40,128,410\}$ & 578 & 5035 & Optimal \\
\hline \multirow{3}{*}{ Models with inspection errors } & 1 & 4 & 141 & $\{141,141,141,141\}$ & 564 & 7036 & $3.39 \%$ \\
\hline & 2 & 3 & 78 & $\{78,250,250\}$ & 578 & 6877 & $1.05 \%$ \\
\hline & 3 & 3 & 42 & $\{38,134,430\}$ & 602 & 6805 & Optimal \\
\hline
\end{tabular}

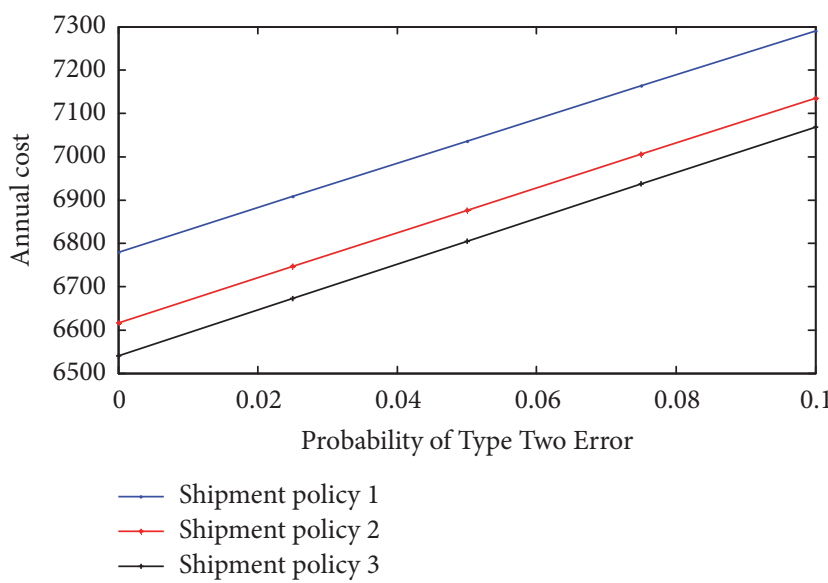

FIGURE 13: Impact of probability of Type Two Error.

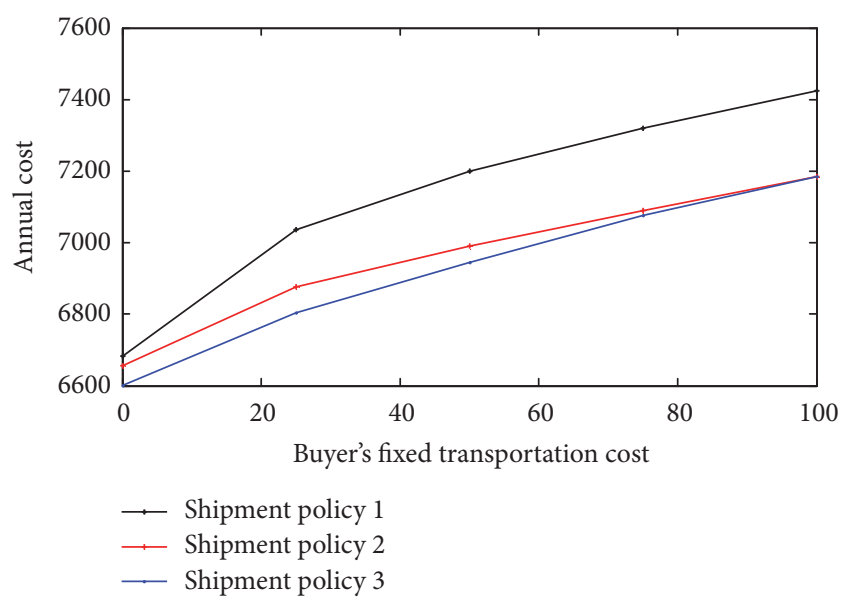

FIGURE 14: Impact of fixed transportation cost.

of misclassifications, all of which show that the proportional size shipment policy is always optimal. Figure 14 exhibits the impact of the fixed transportation cost, from which we know that the proportional size shipment policy is also always optimal. The other parameters' impacts on different shipment policies, including the screening rate and the unit costs incurred by two kinds of misclassifications, which are not displayed for brevity, conform to this observation that

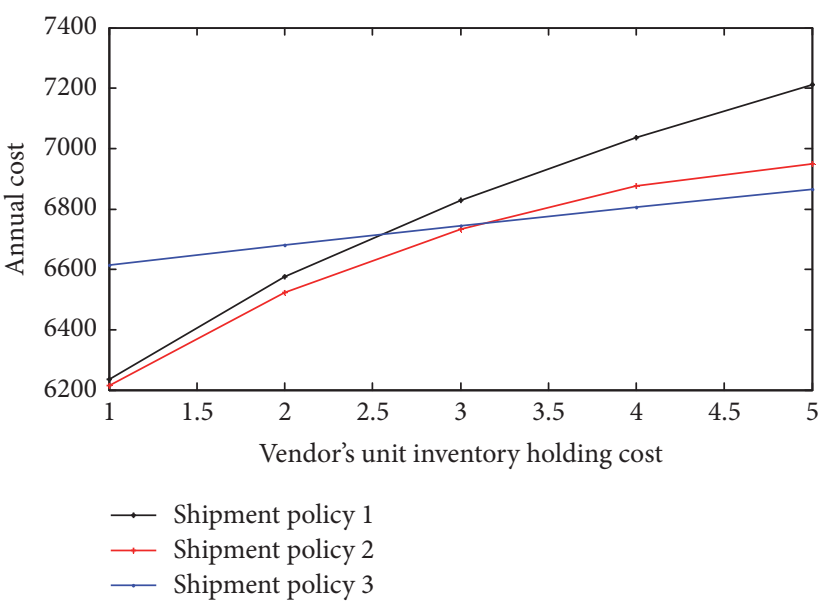

FIGURE 15: Impact of the vendor's unit inventory holding cost.

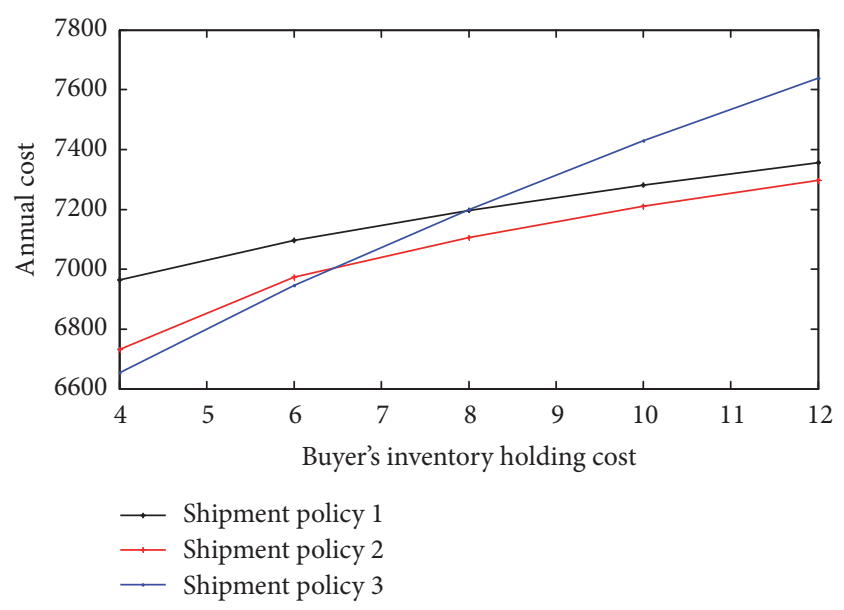

FIGURE 16: Impact of the buyer's unit inventory holding cost.

the proportional size shipment policy is always optimal, no matter how these parameters are selected and what percentage differences of the other shipment policies with respect to this optimal one, except one situation. This exception is brought about by the impacts of the vendor's and the buyer's unit inventory holding costs, as Table 3 and Figures 15 and 16 display. When the vendor's and the 


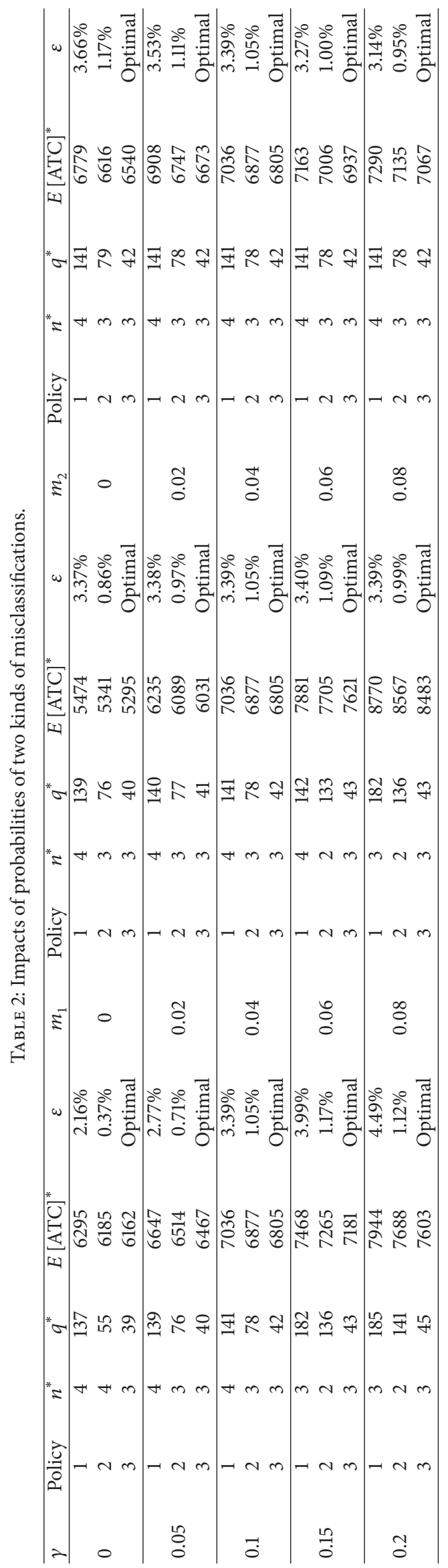


TABLE 3: Impacts of the vendor's and the buyer's unit inventory holding costs.

\begin{tabular}{|c|c|c|c|c|c|c|c|c|c|c|c|}
\hline$h_{v}$ & Policy & $n^{*}$ & $q^{*}$ & $E[\mathrm{ATC}]^{*}$ & $\varepsilon$ & $h_{b}$ & Policy & $n^{*}$ & $q^{*}$ & $E[\mathrm{ATC}]^{*}$ & $\varepsilon$ \\
\hline \multirow{3}{*}{1} & 1 & 9 & 123 & 6234 & $0.31 \%$ & \multirow{3}{*}{4} & 1 & 3 & 185 & 6964 & $4.65 \%$ \\
\hline & 2 & 9 & 42 & 6215 & Optimal & & 2 & 2 & 142 & 6730 & $1.14 \%$ \\
\hline & 3 & 3 & 46 & 6613 & $6.41 \%$ & & 3 & 3 & 45 & 6654 & Optimal \\
\hline \multirow{3}{*}{2} & 1 & 6 & 131 & 6575 & $0.79 \%$ & \multirow{3}{*}{6} & 1 & 4 & 137 & 7096 & $2.18 \%$ \\
\hline & 2 & 6 & 48 & 6524 & Optimal & & 2 & 3 & 75 & 6973 & $0.40 \%$ \\
\hline & 3 & 3 & 45 & 6680 & $2.39 \%$ & & 3 & 3 & 39 & 6945 & Optimal \\
\hline \multirow{3}{*}{3} & 1 & 5 & 131 & 6829 & $1.44 \%$ & \multirow{3}{*}{8} & 1 & 5 & 110 & 7197 & $1.28 \%$ \\
\hline & 2 & 4 & 62 & 6732 & Optimal & & 2 & 5 & 41 & 7106 & Optimal \\
\hline & 3 & 3 & 43 & 6743 & $0.16 \%$ & & 3 & 3 & 35 & 7200 & $1.30 \%$ \\
\hline \multirow{3}{*}{4} & 1 & 4 & 141 & 7036 & $3.39 \%$ & \multirow{3}{*}{10} & 1 & 6 & 92 & 7282 & $1.00 \%$ \\
\hline & 2 & 3 & 78 & 6877 & $1.05 \%$ & & 2 & 6 & 34 & 7209 & Optimal \\
\hline & 3 & 3 & 42 & 6805 & Optimal & & 3 & 3 & 32 & 7429 & $2.96 \%$ \\
\hline \multirow{3}{*}{5} & 1 & 3 & 166 & 7211 & $5.04 \%$ & \multirow{3}{*}{12} & 1 & 7 & 80 & 7357 & $0.83 \%$ \\
\hline & 2 & 2 & 127 & 6950 & $1.24 \%$ & & 2 & 7 & 28 & 7296 & Optimal \\
\hline & 3 & 3 & 40 & 6865 & Optimal & & 3 & 3 & 29 & 7640 & $4.50 \%$ \\
\hline
\end{tabular}

buyer's unit inventory holding costs are relatively close to each other, the proportional size shipment policy is optimal; when they are turning away from each other and reaching a point, the fixed-ratio size shipment policy will become optimal. This observation is understood as follows. During a production run, the proportional size shipment policy can provide the buyer with smaller quantities to "be getting on with" during the early stage and larger quantities during the later stage. When the difference between the vendor's and the buyer's inventory holding costs is quite small, this kind of policy has more advantage in saving more inventory holding cost by shipping more items at the buyer's end and saving the total cost for the integrated system. On the contrary, when it becomes larger, the equal size shipment policy has more advantage in saving more inventory holding cost by keeping more items at the vendor's end and saving the total cost for the integrated system.

\section{Conclusions}

In this paper, we develop the integrated inventory models under the equal size, fixed-ratio size, and proportional size shipment policy for the integrated production-ordering system with imperfect quality items and quality screening committing inspection errors. Our models are a development and extension of the S-J model [16], Khan et al's model [37, 39], and the models dealing with different shipment policies (Lu [5], Goyal and Nebebe [8], and Goyal [6]). We make a comprehensive comparison of different shipment policies so as to select an optimal one for the integrated system and to improve the supply chain's performance. Algorithm procedures, numerical examples, and sensitivity analyses under different shipment policies are provided.

These three different shipment policies are the most employed policies for the integrated supply chain and relatively easy to handle. The equal size shipment policy is the easiest one to handle but is often the least cost-saving, as we can learn from the numerical results; the other two shipment policies are often more cost-saving, even though they involve unequal shipments. In fact, these unequal shipment policies are also easy to handle, since they barely increase the complexity of the optimal algorithms and merely need a multiplier in their shipment structures, the ratio of the production rate and the demand rate, which is given. We do adequate numerical examples to illustrate how different parameters influence the optimality of these different shipment policies for the integrated supply chain in the presence of imperfect quality items and inspection errors. All the numerical results show that the proportional size shipment policy is always optimal, regardless of the degree of the significance of the other shipment policies with regard to this optimal one, except one situation where the difference between the vendor's and the buyer's unit inventory holding costs is considerable. As we have mentioned, the proportional shipment policy barely increases the complexity of the optimal algorithm and merely requires the multiplication of a given factor in its shipment structure but has an overwhelming advantage in saving total cost of the integrated system in nearly all the operational situations. Therefore, in terms of effectiveness and efficiency 
for the decision maker and performance for the supply chain, we recommend the proportional size shipment policy for the integrated system except one situation mentioned above.

\section{Appendix}

Proof of Theorem 1. The first derivative of (36) is given as

$$
\begin{aligned}
\frac{\partial}{\partial q} E[\mathrm{ATP}]= & \frac{\left(A_{v}+A_{b}+n F\right) D}{\left(1-E\left[\gamma_{e}\right]\right) n q^{2}} \\
& +\frac{h_{v}[n-1-(n-2)(D / P)]+h_{b}\left[\left(1-E\left[\gamma_{e}\right]\right)^{2}+2 D E\left[\gamma_{e}\right] / X+E\left[m_{2}\right] E[\gamma](1-E[\gamma])\right]}{2\left(1-E\left[\gamma_{e}\right]\right)},
\end{aligned}
$$

and the second derivative of (36) is given as

$$
\frac{\partial^{2}}{\partial q^{2}} E[\mathrm{ATP}]=\frac{2\left(A_{v}+A_{b}+n F\right) D}{\left(1-E\left[\gamma_{e}\right]\right) n q^{3}} \geq 0
$$

Therefore, (36) is convex with regard to $q$, and we complete proving Theorem 1 . In order to get the optimal result of (36), letting $(\partial / \partial q) E[\mathrm{ATP}]=0$, we get the optimal $q^{*}$, which is given as

$$
q^{*}=\sqrt{\frac{2\left(A_{v}+A_{b}+n F\right) D}{n\left\{h_{v}[n-1-(n-2)(D / P)]+h_{b}\left[\left(1-E\left[\gamma_{e}\right]\right)^{2}+2 D E\left[\gamma_{e}\right] / X+E\left[m_{2}\right] E[\gamma](1-E[\gamma])\right]\right\}}}
$$

Proof of Theorem 3. The first derivative of (38) is given as

$$
\begin{aligned}
& \frac{\partial}{\partial q} E[\mathrm{ATP}]=\frac{\left(A_{v}+A_{b}+n F\right) D}{\left(1-E\left[\gamma_{e}\right]\right)[1+(n-1) \beta] q^{2}} \\
& \quad+\frac{h_{v}\left\{\beta(n-1)[2+(n-2) \beta]-\left([(n-1) \beta]^{2}-1\right) / \beta\right\}+h_{b}\left[1+(n-1) \beta^{2}\right]\left(2 D E\left[\gamma_{e}\right] / X+E\left[\left(1-\gamma_{e}\right)^{2}\right]+E\left[m_{2}\right] E[\gamma](1-E[\gamma])\right)}{2[1+(n-1) \beta]\left(1-E\left[\gamma_{e}\right]\right)},
\end{aligned}
$$

and the second derivative of (38) is given as

$$
\frac{\partial^{2}}{\partial q^{2}} E[\mathrm{ATP}]=\frac{2\left(A_{v}+A_{b}+n F\right) D}{\left(1-E\left[\gamma_{e}\right]\right)[1+(n-1) \beta] q^{3}} \geq 0
$$

Therefore, (38) is convex with regard to $q$, and we complete proving Theorem 3. In order to get the optimal result of (38), letting $(\partial / \partial q) E[$ ATP $]=0$, we get the optimal $q^{*}$, which is given as

$$
=\sqrt{\frac{q^{*}}{h_{v}\left\{\beta(n-1)[2+(n-2) \beta]-\left([(n-1) \beta]^{2}-1\right) / \beta\right\}+h_{b}\left[1+(n-1) \beta^{2}\right]\left[2 D E\left[\gamma_{e}\right] / X+E\left[\left(1-\gamma_{e}\right)^{2}\right]+E\left[m_{2}\right] E[\gamma](1-E[\gamma])\right]}} .
$$

Proof of Theorem 5. The first derivative of (40) is given as

$$
\begin{aligned}
\frac{\partial}{\partial q} E[\mathrm{ATP}]= & \frac{\left(A_{v}+A_{b}+n F\right) D}{\left(1-E\left[\gamma_{e}\right]\right)\left(\left(\beta^{n}-1\right) /(\beta-1)\right) q^{2}} \\
& +\frac{\left(\left(\beta^{n}+1\right) /(\beta+1)\right)\left\{h_{v} / \beta+h_{b}\left[2 D E\left[\gamma_{e}\right] / X+E\left[\left(1-\gamma_{e}\right)^{2}\right]+E\left[m_{2}\right] E[\gamma](1-E[\gamma])\right]\right\}}{2\left(1-E\left[\gamma_{e}\right]\right)},
\end{aligned}
$$


and the second derivative of (40) is given as

$$
\begin{aligned}
\frac{\partial^{2}}{\partial q^{2}} E[\mathrm{ATP}] & =\frac{2\left(A_{v}+A_{b}+n F\right) D}{\left(1-E\left[\gamma_{e}\right]\right)\left(\left(\beta^{n}-1\right) /(\beta-1)\right) q^{3}} \\
& \geq 0 .
\end{aligned}
$$

Therefore, (40) is convex with regard to $q$, and we complete proving Theorem 5. In order to get the optimal result of (40), letting $(\partial / \partial q) E[\mathrm{ATP}]=0$, we get the optimal $q^{*}$, which is given as

$$
q^{*}=\sqrt{\frac{2\left(A_{v}+A_{b}+n F\right) D}{\left(\left(\beta^{2 n}-1\right) /\left(\beta^{2}-1\right)\right)\left\{h_{v} / \beta+h_{b}\left[2 D E\left[\gamma_{e}\right] / X+E\left[\left(1-\gamma_{e}\right)^{2}\right]+E\left[m_{2}\right] E[\gamma](1-E[\gamma])\right]\right\}}} .
$$

\begin{tabular}{|c|c|}
\hline$P:$ & Vendor's production rate (units/year) \\
\hline$D:$ & Buyer's demand rate (units/year) \\
\hline$\beta:$ & Ratio of $P / D$ \\
\hline$y:$ & Unit selling price of a nondefective item \\
\hline$z$ : & Unit selling price of a defective item \\
\hline$A_{v}:$ & Vendor's fixed setup cost (\$/cycle) \\
\hline$A_{b}:$ & Buyer’s fixed ordering cost (\$/cycle) \\
\hline$h_{v}:$ & Vendor's unit holding cost (\$/unit/year) \\
\hline$h_{b}:$ & Buyer's unit holding cost (\$/unit/year) \\
\hline$s:$ & Buyer's unit screening cost $(\$)$ \\
\hline$X:$ & Buyer's screening rate (units/year) \\
\hline$v:$ & $\begin{array}{l}\text { Buyer's transportation cost per unit } \\
\text { shipped }(\$)\end{array}$ \\
\hline$F:$ & $\begin{array}{l}\text { Buyer's fixed transportation cost per } \\
\text { shipment }(\$)\end{array}$ \\
\hline$p:$ & $\begin{array}{l}\text { Vendor's production cost per unit time } \\
\text { (\$/year) }\end{array}$ \\
\hline$T:$ & Time length of a production cycle (year) \\
\hline$n:$ & $\begin{array}{l}\text { Number of shipments from the vendor to } \\
\text { the buyer in a production cycle (a decision } \\
\text { variable) }\end{array}$ \\
\hline$q:$ & $\begin{array}{l}\text { The first shipment size from the vendor to } \\
\text { the buyer in a production cycle (a decision } \\
\text { variable) }\end{array}$ \\
\hline$q_{i}:$ & $\begin{array}{l}\text { The } i \text { th shipment size from the vendor to } \\
\text { the buyer in a production cycle }\end{array}$ \\
\hline$W:$ & $\begin{array}{l}\text { Total batch size from the vendor to the } \\
\text { buyer in a production cycle }\end{array}$ \\
\hline$\gamma:$ & $\begin{array}{l}\text { Random variable representing fraction of } \\
\text { defective items }\end{array}$ \\
\hline$f(\gamma):$ & Probability density function of $\gamma$ \\
\hline$m_{1}:$ & $\begin{array}{l}\text { Random variable representing Type One } \\
\text { Error }\end{array}$ \\
\hline$m_{2}:$ & $\begin{array}{l}\text { Random variable representing Type Two } \\
\text { Error }\end{array}$ \\
\hline$\gamma_{e}:$ & $\begin{array}{l}\text { Fraction of defective items observed by } \\
\text { the buyer after screening, }\end{array}$ \\
\hline $\begin{array}{l}f\left(m_{1}\right): \\
f\left(m_{2}\right):\end{array}$ & $\begin{array}{l}\gamma_{e}=(1-\gamma) m_{1}+\gamma\left(1-m_{2}\right) \\
\text { Probability density function of } m_{1} \\
\text { Probability density function of } m_{2}\end{array}$ \\
\hline$c_{r}:$ & $\begin{array}{l}\text { Cost of falsely rejecting a nondefective } \\
\text { item (units/year) }\end{array}$ \\
\hline$c_{a}:$ & $\begin{array}{l}\text { Cost of falsely accepting a defective item } \\
\text { (units/year) }\end{array}$ \\
\hline
\end{tabular}

\section{Notation}

$B_{i}$ : Number of items classified as defective in the $i$ th delivering cycle

$E_{i}$ : Number of defective items returned from the market in the $i$ th delivering cycle.

\section{Conflicts of Interest}

The authors declare that they have no conflicts of interest.

\section{Acknowledgments}

This research was supported by the National Natural Science Foundation of China with Grant no. G71520107001.

\section{References}

[1] S. K. Goyal, "An integrated inventory model for a singles upplier-single customer problem," International Journal of Production Research, vol. 15, no. 1, pp. 107-111, 1977.

[2] S. K. Goyal, "Determination of optimum production quantity for a two-stage production system," Journal of the Operational Research Society, vol. 28, no. 4, pp. 865-870, 1977.

[3] S. K. Goyal, "A joint economic-lot-size model for purchaser and vendor: a comment," Decision Sciences, vol. 19, no. 1, pp. 236$241,1988$.

[4] A. Banerjee, "A joint economic-lot-size model for purchaser and vendor," Decision Sciences, vol. 17, no. 3, pp. 292-311, 1986.

[5] L. Lu, "A one-vendor multi-buyer integrated inventory model," European Journal of Operational Research, vol. 81, no. 2, pp. 312323, 1995.

[6] S. K. Goyal, "A one-vendor multi-buyer integrated inventory model: a comment," European Journal of Operational Research, vol. 82, no. 1, pp. 209-210, 1995.

[7] R. M. Hill, "The single-vendor single-buyer integrated production-inventory model with a generalised policy," European Journal of Operational Research, vol. 97, no. 3, pp. 493-499, 1997.

[8] S. K. Goyal and F. Nebebe, "Determination of economic production-shipment policy for a single-vendor-single-buyer system," European Journal of Operational Research, vol. 121, no. 1, pp. 175$178,2000$.

[9] R. M. Hill, “The optimal production and shipment policy for the singke-vendor singlebuyer integrated production-inventory problem," International Journal of Production Research, vol. 37, no. 11, pp. 2463-2475, 1999. 
[10] S. K. Goyal and A. Z. Szendrovits, "A constant lot size model with equal and unequal sized batch shipments between production stages," Engineering Costs and Production Economics, vol. 10, no. 3, pp. 203-210, 1986.

[11] H. Siajadi, R. N. Ibrahim, and P. B. Lochert, "A single-vendor multiple-buyer inventory model with a multiple-shipment policy," International Journal of Advanced Manufacturing Technology, vol. 27, no. 9-10, pp. 1030-1037, 2006.

[12] Y.-W. Zhou and S.-D. Wang, "Optimal production and shipment models for a single-vendor-single-buyer integrated system," European Journal of Operational Research, vol. 180, no. 1, pp. 309-328, 2007.

[13] H. L. Lee and M. J. Rosenblatt, "Simultaneous determination of production cycle and inspection schedules in a production system," Management Science, vol. 33, no. 9, pp. 1125-1136, 1987.

[14] C. A. Yano and H. L. Lee, "Lot sizing with random yields: a review," Operations Research, vol. 43, no. 2, pp. 311-334, 1995.

[15] M. Ben-Daya and A. Rahim, "Optimal lot-sizing, quality improvement and inspection errors for multistage production systems," International Journal of Production Research, vol. 41, no. 1, pp. 65-79, 2003.

[16] M. K. Salameh and M. Y. Jaber, "Economic production quantity model for items with imperfect quality," International Journal of Production Economics, vol. 64, no. 1, pp. 59-64, 2000.

[17] B. Maddah and M. Y. Jaber, "Economic order quantity for items with imperfect quality: revisited," International Journal of Production Economics, vol. 112, no. 2, pp. 808-815, 2008.

[18] M. Y. Jaber, S. Zanoni, and L. E. Zavanella, "An entropic economic order quantity (EnEOQ) for items with imperfect quality," Applied Mathematical Modelling, vol. 37, no. 6, pp. 3982-3992, 2013.

[19] S. K. Goyal, C.-K. Huang, and K.-C. Chen, "A simple integrated production policy of an imperfect item for vendor and buyer," Production Planning and Control, vol. 14, no. 7, pp. 596-602, 2003.

[20] L.-Y. Ouyang, K.-S. Wu, and C.-H. Ho, "Analysis of optimal vendor-buyer integrated inventory policy involving defective items," International Journal of Advanced Manufacturing Technology, vol. 29, no. 11-12, pp. 1232-1245, 2006.

[21] J. Rezaei and M. Davoodi, "A deterministic, multi-item inventory model with supplier selection and imperfect quality," Applied Mathematical Modelling, vol. 32, no. 10, pp. 2106-2116, 2008.

[22] M. Y. Jaber, S. K. Goyal, and M. Imran, "Economic production quantity model for items with imperfect quality subject to learning effects," International Journal of Production Economics, vol. 115, no. 1, pp. 143-150, 2008.

[23] M. Khan, M. Y. Jaber, and M. I. M. Wahab, "Economic order quantity model for items with imperfect quality with learning in inspection," International Journal of Production Economics, vol. 124, no. 1, pp. 87-96, 2010.

[24] I. Konstantaras, K. Skouri, and M. Y. Jaber, "Inventory models for imperfect quality items with shortages and learning in inspection," Applied Mathematical Modelling, vol. 36, no. 11, pp. 5334-5343, 2012.

[25] T.-Y. Lin, "An economic order quantity with imperfect quality and quantity discounts," Applied Mathematical Modelling. Simulation and Computation for Engineering and Environmental Systems, vol. 34, no. 10, pp. 3158-3165, 2010.

[26] Y.-W. Zhou, J. Chen, Y. Wu, and W. Zhou, "EPQ models for items with imperfect quality and one-time-only discount," Applied Mathematical Modelling, vol. 39, no. 3-4, pp. 1000-1018, 2015.
[27] K.-J. Chung, "The 'EOQ model with defective items and partially permissible delay in payments linked to order quantity derived analytically in the supply chain management," Applied Mathematical Modelling, vol. 37, no. 4, pp. 2317-2326, 2013.

[28] M. Y. Jaber, S. Zanoni, and L. E. Zavanella, "Economic order quantity models for imperfect items with buy and repair options," International Journal of Production Economics, vol. 155, pp. 126-131, 2014.

[29] B. Mondal, A. K. Bhunia, and M. Maiti, "Inventory models for defective items incorporating marketing decisions with variable production cost," Applied Mathematical Modelling, vol. 33, no. 6, pp. 2845-2852, 2009.

[30] H.-C. Chang, "A comprehensive note on: an economic order quantity with imperfect quality and quantity discounts," Applied Mathematical Modelling, vol. 35, no. 10, pp. 5208-5216, 2011.

[31] L. Moussawi-Haidar, M. Salameh, and W. Nasr, "Effect of deterioration on the instantaneous replenishment model with imperfect quality items," Applied Mathematical Modelling. Simulation and Computation for Engineering and Environmental Systems, vol. 38, no. 24, pp. 5956-5966, 2014.

[32] Y. Zhou and Z. Lin, "Inventory replenishment policy for the decision maker with present-biased preference and timeinconsistency under inflation," Journal of Systems Science and Systems Engineering, vol. 26, no. 5, pp. 628-645, 2017.

[33] A. Eroglu and G. Ozdemir, "An economic order quantity model with defective items and shortages," International Journal of Production Economics, vol. 106, no. 2, pp. 544-549, 2007.

[34] J.-T. Hsu and L.-F. Hsu, "An integrated vendor-buyer cooperative inventory model for items with imperfect quality and shortage backordering," Advances in Decision Sciences, vol. 2012, Article ID 679083, 9 pages, 2012.

[35] S. S. Sana, "A production-inventory model of imperfect quality products in a three-layer supply chain," Decision Support Systems, vol. 50, no. 2, pp. 539-547, 2011.

[36] M. Khan, M. Y. Jaber, A. L. Guiffrida, and S. Zolfaghari, "A review of the extensions of a modified EOQ model for imperfect quality items," International Journal of Production Economics, vol. 132, no. 1, pp. 1-12, 2011.

[37] M. Khan, M. Y. Jaber, and M. Bonney, "An economic order quantity (EOQ) for items with imperfect quality and inspection errors," International Journal of Production Economics, vol. 133, no. 1, pp. 113-118, 2011.

[38] J.-T. Hsu and L.-F. Hsu, "An EOQ model with imperfect quality items, inspection errors, shortage backordering, and sales returns," International Journal of Production Economics, vol. 143, no. 1, pp. 162-170, 2013.

[39] M. Khan, M. Y. Jaber, and A. Ahmad, "An integrated supply chain model with errors in quality inspection and learning in production," Omega, vol. 42, no. 1, pp. 16-24, 2014.

[40] S. K. Goyal, "On improving the single-vendor single-buyer integrated production inventory model with a generalized policy," European Journal of Operational Research, vol. 125, no. 2, pp. 429-430, 2000. 


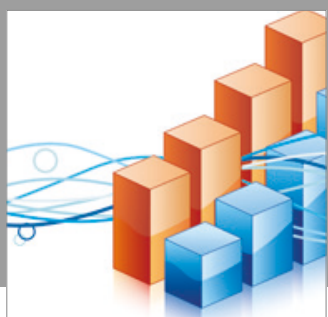

Advances in

Operations Research

vatersals

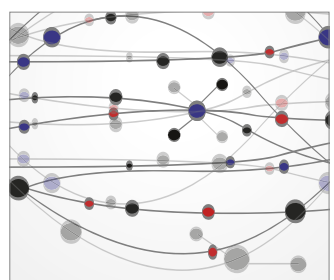

\section{The Scientific} World Journal
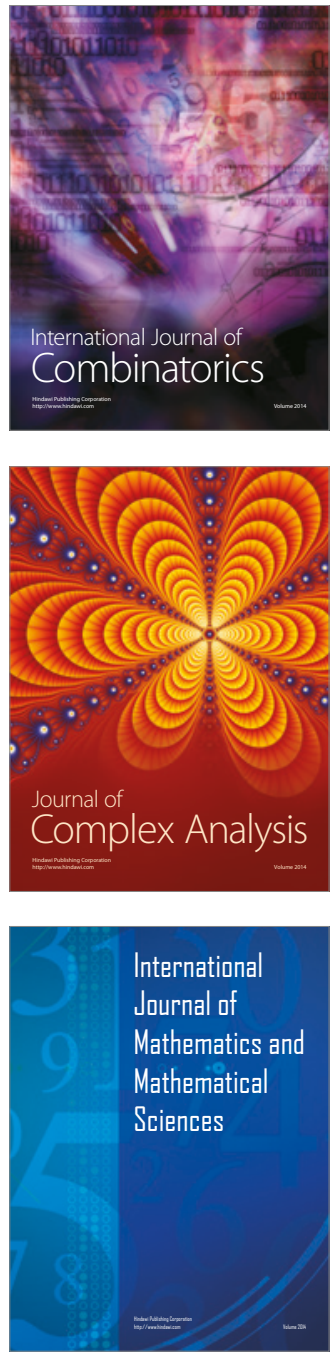
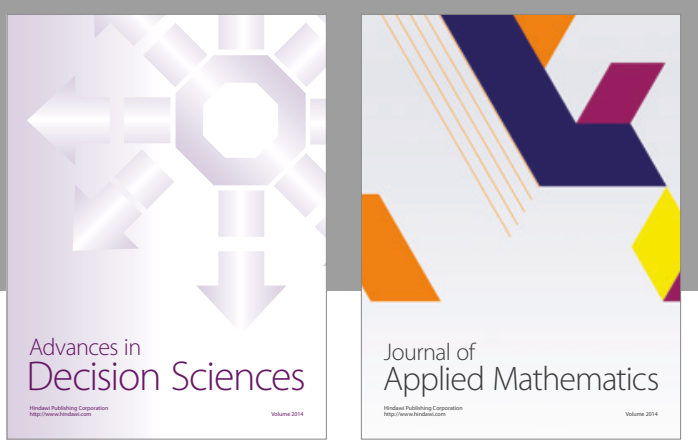

Algebra

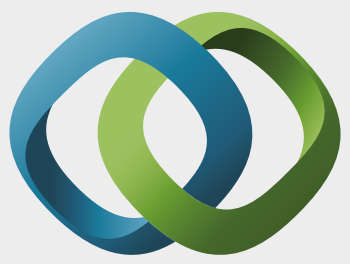

\section{Hindawi}

Submit your manuscripts at

https://www.hindawi.com
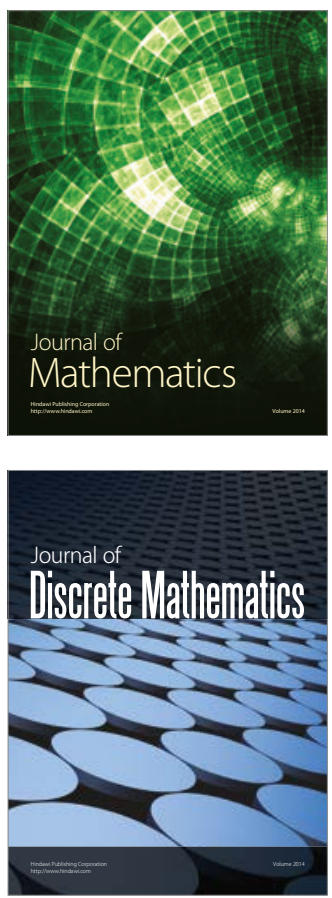

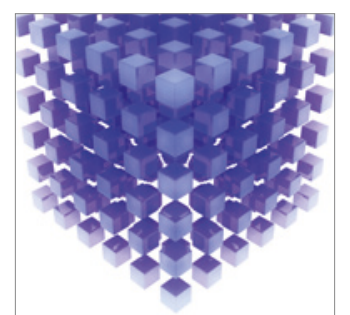

Mathematical Problems in Engineering
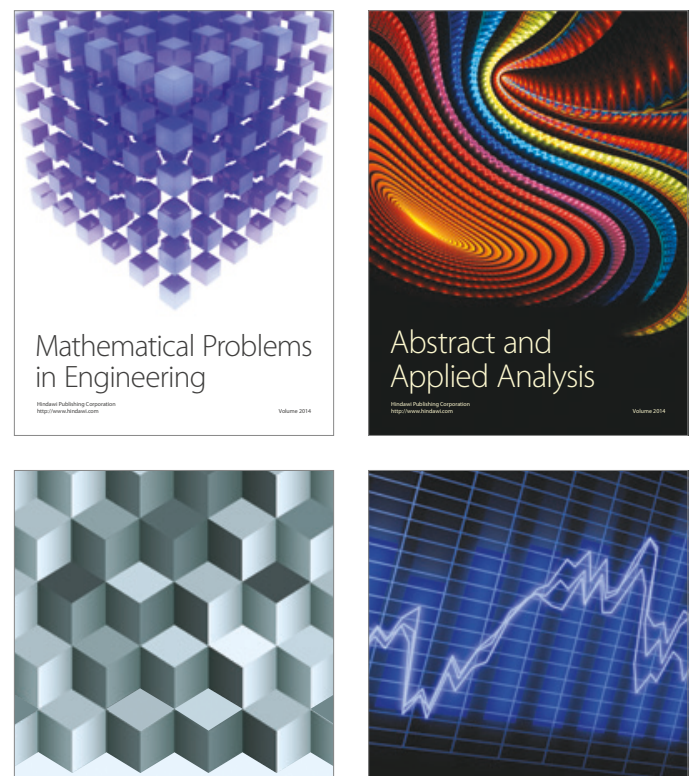

Journal of

Function Spaces

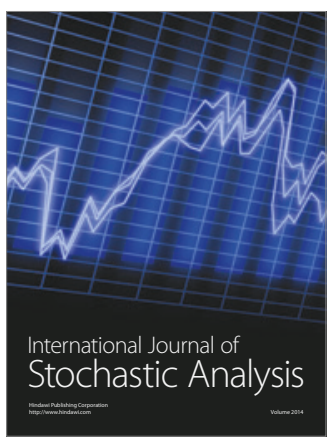

Probability and Statistics
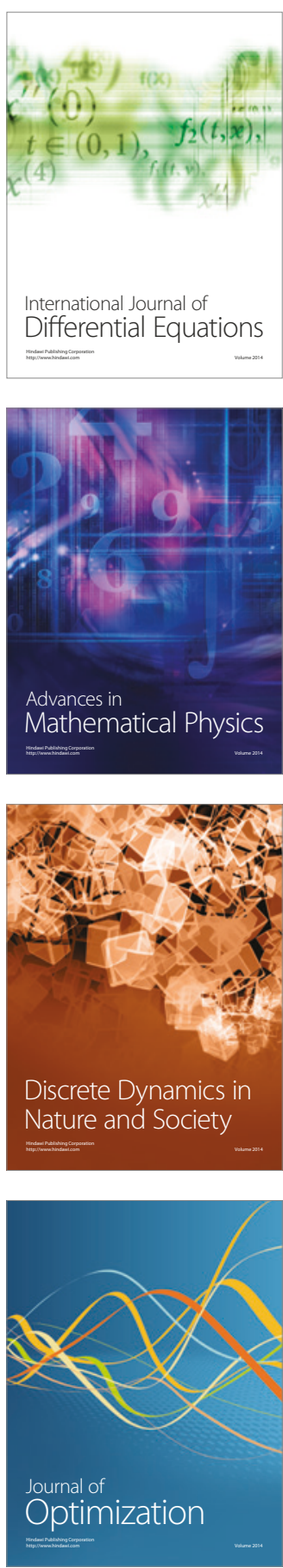